\title{
Controls on trace-element partitioning in cave-analogue calcite
}

\author{
Christopher C. Day and Gideon M. Henderson
}

Department of Earth Sciences, University of Oxford, South Parks Road, OX1 3AN, UK

\begin{abstract}
We report trace-element data from a series of carbonate growth experiments in cave-analogue conditions in the laboratory with the goal of better understanding environmental controls on trace-element incorporation in stalagmites. The experimental setup closely mimics natural processes (e.g. precipitation driven by $\mathrm{CO}_{2}$-degassing, low ionic strength solution, thin solution-film) but with a tight control on growth conditions (temperature, $\mathrm{pCO}_{2}$, drip rate, calcite saturation index and the composition of the initial solution). Calcite is dissolved in deionized water in a 20,000 ppmV $p \mathrm{CO}_{2}$ environment, with trace-elements ( $\left.\mathrm{Li}, \mathrm{Na}, \mathrm{Mg}, \mathrm{Co}, \mathrm{Sr}, \mathrm{Cd}, \mathrm{Ba}, \mathrm{U}\right)$ at appropriate concentrations to mimic natural cave drip-waters. This solution is dripped onto glass plates (coated with seed-calcite) in a lower $\mathrm{pCO}_{2}$ environment at $7,15,25$ and $35^{\circ} \mathrm{C}$ and drip rates of 2,6 and 10 drips per minute. $\mathrm{D}(\mathrm{Sr})$ was shown to be statistically invariant over the full range of temperature and growth rate studied. No relationship between $\mathrm{Sr} / \mathrm{Ca}$ and growth rate is therefore expected in stalagmite samples over comparable growth rates. $\mathrm{D}(\mathrm{Mg})$ has a relationship with temperature defined by $D(M g)=0.01 e^{0.02[ \pm 0.006] T}$, but temperature is not expected to be the dominant control on $\mathrm{Mg} / \mathrm{Ca}$ in cave calcite due to the larger impact of calcite precipitation on $\mathrm{Mg} / \mathrm{Ca}$. Over short timescales, in conditions where temperature is well buffered, the fraction of calcium remaining in solution $(f)$ is likely to be the dominant control on $\mathrm{Mg} / \mathrm{Ca}$ and other trace-element ratios. But differences in the response of trace-elements to $f$ and $T$ may allow their combined use to assess past cave conditions. High $C d / C a_{\text {stalagmite }}$ is particularly indicative of low amounts of prior calcite precipitation and $\mathrm{Cd} / \mathrm{Ca}$ would be a useful addition to traceelement studies of natural stalagmites. Significant scatter is observed in trace-element ratios during the laboratory experiments, which cannot be explained by simple Rayleigh distillation. This scatter is well explained by solution mixing and by the mixing of calcite with different fractions of calcite growth. Accounting for the effects of mixing on trace-element concentrations or ratios may help to achieve more robust interpretations of stalagmite chemistry as part of a multi-proxy approach to assessment of past environments.
\end{abstract}

Keywords: trace-element partitioning, stalagmite, speleothem, palaeoclimate proxy, palaeoclimate

Email address: chris.day@earth.ox.ac.uk (Christopher C. Day and Gideon M. Henderson) 
reconstruction, paleoclimate, cave-analogue calcite growth 


\title{
Controls on trace-element partitioning in cave-analogue calcite
}

\author{
Christopher C. Day and Gideon M. Henderson
}

Department of Earth Sciences, University of Oxford, South Parks Road, OX1 3AN, UK

\section{1. Introduction}

2 The high-resolution nature of speleothem records (sub-annual in some cases, e.g. Johnson et al., 2006; Orland et al.,

3 2012), the absolute chronology of their growth layers established with U-Th and U-Pb radiometric dating, and their

${ }_{4}$ extensive geographical coverage (including human-habited areas) ensure that speleothem samples are a fundamen-

5 tal tool for terrestrial palaeoclimate reconstruction and for understanding climate-system mechanisms.

6 Progress in the coverage and interpretation of speleothem measurements is gradually allowing for the combina-

7 tion of absolute chronology and palaeoclimate proxies to test climatic teleconnections between geographically

8 distinct speleothem records (e.g. Wang et al., 2004). Defining the nature of climate events for spatial and tem-

9 poral comparison of records requires robust proxies. There is an increasing number of proxies applicable to

10 speleothem samples. Oxygen isotope measurements of speleothem-growth is the most widely used proxy (e.g.

11 Hendy, 1971; McDermott et al., 2011). Absolute chronology of speleothem growth versus no-growth can be used

12 to infer periods of warmer or wetter periods in a region's history when environmental conditions are amenable to

13 speleothem growth (Lauritzen, 1995; Burns et al., 2001; Vaks et al., 2010; Meyer et al., 2012; Vaks et al., 2013).

${ }_{14}$ A range of other proxies have been used, including $\delta^{13} C$ (e.g. Dorale et al., 1992; Genty et al., 2006), pollen

15 (e.g. Bastin, 1978; Camacho et al., 2000), speleothem petrography and mineralogy (e.g. Railsback et al., 1994;

16 Turgeon \& Lundberg, 2001; Frisia et al., 2002; Railsback et al., 2011) and fluorescence (e.g. Baker \& Genty, 1999; Tan et al., 2006; Ishii \& Boyer, 2012; Orland et al., 2012). Trace-elements also respond to environmental variables and have been the focus of previous work (e.g. Huang et al., 2001; Treble et al., 2005; Johnson et al., 2006). Trace-element incorporation at the speleothem surface is understood to respond to a number of factors, including i) temperature (e.g. Gascoyne, 1983; Huang \& Fairchild, 2001); ii) the growth rate of calcite (e.g.

21 Morse \& Bender, 1990); and iii) characteristics of the drip solution, e.g. Na outcompeting Sr for non-lattice sites (Pingitore \& Eastman, 1986). Despite a long history of research on trace-element partitioning into calcite

Email address: chris.day@earth.ox.ac.uk (Christopher C. Day and Gideon M. Henderson) 
(e.g. Gascoyne, 1983; Paquette \& Reeder, 1995; Tesoriero \& Pankow, 1996; Tang et al., 2008), many uncer-

24 tainties remain regarding the controls on trace-element incorporation into speleothem calcite. A key limitation

25 is the non-thermodynamic nature of partition coefficients during calcite precipitation in most natural contexts

26 (Morse \& Bender, 1990). This requires the partitioning behaviour to be established for speleothem-specific conditions. Yet for many elements, partition coefficients are only available from marine-type studies or from calcite

37 2.1. Trace-element experimental setup precipitation in caves in non-controlled growth conditions. There is currently only one laboratory study reporting trace-element results (Huang \& Fairchild, 2001), which replicates the low ionic-strength, thin solution-film environment in which speleothem calcite precipitates. That study reports partition coefficients only for $\mathrm{Mg}$ and $\mathrm{Sr}$ and has uncharacteristically high $\mathrm{Na}^{+}$and $\mathrm{Cl}^{-}$concentrations, which could have repercussions on the incorporation of trace-elements (e.g. Pingitore \& Eastman, 1986).

In this study, we present the trace-element results of laboratory experiments in which we grew calcite in conditions that closely replicate natural cave processes. The goal is to better understand the environmental controls on stalagmite trace-element incorporation to aid robust palaeoclimate interpretation.

\section{Methods}

Complete details of the experimental setup are provided in Day \& Henderson (2011). Here we provide a brief overview, and focus on the details that relate specifically to the study of trace-element incorporation.

40 The setup closely mimics natural stalagmite formation (e.g. precipitation driven by $\mathrm{CO}_{2}$-degassing, low ionic 41 strength solution, thin solution-film) but with a tight control on growth conditions (temperature, $\mathrm{pCO}_{2}$, drip rate,

42 calcite saturation index and the composition of the initial solution). We use two reaction vessels, one with high ${ }_{43} \mathrm{pCO}_{2}\left(20,000 \mathrm{ppmV}\right.$, the 'dissolution chamber') and one with low $p \mathrm{CO}_{2}(<2,500 \mathrm{ppmV}$, the 'precipitation cham44 ber'). Solution from the dissolution chamber, with a controlled calcite saturation index $\left(S I_{\text {calcite }}\right)$ of 0.34 is pumped, ${ }_{45}$ by peristaltic pump, to drip onto seeded glass plates in the precipitation chamber, where $\mathrm{CO}_{2}$-degassing from so46 lution drives calcite growth.

47 The solution is prepared as a mixture of $18 M \Omega$ deionized water, VWR AnalR calcite and a solution containing 48 a pre-determined mix of trace-elements sourced from 'High-Purity Standards' single-element standards (table 1).

49 The calcite (calculated and weighed for each temperature) is dissolved by bubbling pure $\mathrm{CO}_{2}$ through the solution so under a $100 \% \mathrm{CO}_{2}$ atmosphere, with continual overhead stirring. After complete calcite dissolution (as verified ${ }_{51}$ by visual inspection and $\mathrm{pH}$ monitoring), the solution was equilibrated with a headspace $p C \mathrm{O}_{2}$ of $20,000 \mathrm{ppmV}$ 
52 (as verified by solution $\mathrm{pH}$ and headspace $\mathrm{pCO}_{2}$ measurements) and maintained at these conditions throughout

53 the subsequent growth experiments. A set of naturally-representative drip-solution concentrations was selected

54 (table 1) and the conditions maintained constant in all experiments of this study. For two experiments at 7 and $15^{\circ} \mathrm{C}$, sulphate was also included in the solution of trace-elements to determine the partition coefficient for sulphur but this addition caused precipitation of $\mathrm{BaSO}_{4}$ and removed Co as a co-precipitate. This disadvantageous effect was to cause inconsistently low $\mathrm{Co}$ and $\mathrm{Ba}$ concentrations for these 7 and $15^{\circ} \mathrm{C}$ experiments and therefore valid experimental results for $\mathrm{Co}$ and $\mathrm{Ba}$ are limited to the two high-temperature experiments $\left(25\right.$ and $\left.35^{\circ} \mathrm{C}\right)$. Because $\mathrm{CO}_{2}$-solubility decreases with increasing temperature, it is not possible to maintain both $\left[\mathrm{Ca}^{2+}\right]$ and the calcite saturation index $\left(S I_{\text {calcite }}\right)$ constant over the full range of experiments $\left(7-35^{\circ} \mathrm{C}\right)$. A $S I_{\text {calcite }}$ of 0.34 was selected as being representative of the natural environment (Baker et al., 1998) and was kept constant by decreasing $\left[\mathrm{Ca}^{2+}\right]$ with increasing experimental temperature. $\mathrm{X} / \mathrm{C} a_{\text {solution }}$ was kept constant between experiments by decreasing the concentration of trace-elements in the same fraction as for calcium (table 1).

To guard against precipitation of calcite in the supply tubes during pumping of the solution from the dissolution vessel to the precipitation chamber, the length of tubing was minimized and narrow gauge PTFE tubing was used everywhere (except for the peristaltic pump tubing) to minimize residence time of solution within the tubes. This is important to ensure that partition coefficients measured on the glass plates are not affected by calcite precipitation earlier in the system. Subsequent to each experiment, nitric acid was pumped slowly through all of the tubing and collected for $[\mathrm{Ca}]_{\text {solution }}$ measurement. The largest mass of calcite recovered this way was $0.045 \mathrm{mg}$. This amount is trivial relative to the $2890 \mathrm{mg}$ of dissolved calcite flowing through the system, therefore providing confidence that calcite precipitation prior to the glass plate is not affecting the glass plate chemistry.

Within the precipitation chamber, calcite is grown on glass plates $(76 \times 52 \mathrm{~mm})$ placed on in-built supports, all tilted at the same angle $\left(12^{\circ}\right)$, to prevent thick solution-films that would otherwise form on horizontal plates as a result of surface tension. The glass plates were first seeded with calcium carbonate (cf. Day \& Henderson, 2011) because seeded growth is more representative of natural growth conditions and because the presence of seed material closely matched to the precipitating material reduces the energy barrier required for solid precipitation to occur (Steefel, 1990; Stumm \& Morgan, 1996; Lin, 2005; Lin, 2005). Based on SEM imagery (cf. Day \& Henderson, 2011) the seed material is dominated by well-defined calcite rhombs, the largest of which approach $100 \mu \mathrm{m}$ in length, and also contains a minor amount of aragonite and perhaps some vaterite. Because of the presence of seed carbonate, all $\mathrm{X} / \mathrm{Ca}$ measurements constitute a mixture of seed and sample material. Seed calcite is free of trace-elements except for Eu, which is added to enable the proportion of seed in final mixtures to be calculated. Correction for the presence of seed material is detailed in Supplementary Information Section 1. 
83 Experiments were conducted at $7,15,25$ and $35^{\circ} \mathrm{C}$. At each temperature, experiments were conducted simultane-

84 ously at three drip rates, $1.6 \pm 0.1$ ('slow'), $5.8 \pm 0.2$ ('medium') and $10.4 \pm 0.5$ ('fast') drips $\min ^{-1}(2 \sigma, \mathrm{n}=30$

${ }_{85}$ independent measurements of drip rate), resulting in a total of 12 experiments, each of 7-day duration. These three drip rates correspond to average flow rates of 0.13,0.67 and $1.29 \mathrm{~mL} \mathrm{~min}^{-1}$. Samples were retrieved from three areas on each plate, referred to as the 'splash', 'flow' and 'ponded' zones (cf. figure 1). We therefore report on a total of 36 measurements of trace-elements in calcite (i.e. four temperatures, three drip rates and three locations on each plate).

\subsection{Sample recovery}

91 On completion of the three synchronous drip-rate experiments at a given temperature, the glass plates were care-

92 fully rinsed with a small volume of deionized water to ensure that any metals remaining in the initial solution were

93 rinsed away. The plates were dried overnight in an oven at $60^{\circ} \mathrm{C}$, allowed to re-equilibrate with ambient conditions

94 and then weighed to establish the mass of calcite growth. The mixture of seed and sample was then scraped from

95 each of the ponded, flow and splash zones in turn (cf. figure 1 for illustration of plate layout), whilst both the plate and the recovered $\mathrm{CaCO}_{3}$ were weighed on each occasion to establish the mass of carbonate within each area. The $\mathrm{CaCO}_{3}$ was stored in acid-washed plastic centrifuge tubes. The SEM area of each plate (figure 1) was used for in-situ SEM imagery of sample growth, which shows overgrowth of calcite rhombs on the carbonate seed (cf. Day \& Henderson, 2011) as expected from the greater supersaturation of calcite $\left(S I_{\text {calcite }}=0.34\right)$ compared to aragonite $\left(S I_{\text {aragonite }}=0.20\right)$, calculated using PHREEQC (Parkhurst \& Appelo, 1999).

\subsection{Trace-element measurements}

Element/Ca ratios for $\mathrm{Li}, \mathrm{Na}, \mathrm{Mg}, \mathrm{Co}, \mathrm{Sr}, \mathrm{Cd}, \mathrm{Ba}$ and U ratios were measured using the 'ratio' method (Lea \& Martin, 1996; Rosenthal et al., 1999) on a Thermo-Finnigan MAT Element 2 sector field ICPMS, with a $130 \mu L / m i n$ nebulizer and an Aridus desolvation unit. All samples were acidified to $2 \% \mathrm{HNO}_{3}$ using distilled $\mathrm{HNO}_{3}$ and diluted so that $\mathrm{Ca}$ concentrations were equal to those of the external, matrix-matched standards. All elements were measured at a resolution of $300[\mathrm{~m} / \Delta m]$. Sample measurements were standard-bracketed. Three types of multi-element standards bracketed the different compositional nature of i) initial solutions; ii) the seeds and; iii) the samples. All trace-elements in these multi-element standards are sourced from single-element 'High-Purity Standards' standards for which the accuracy is certified against NIST Spectrometric Standard Solutions. The external error $( \pm 2 S D)$ for $(X / C a)$ of material scraped from the plate after each experiment $\left(X / C a_{m i x}\right)$ is characterized by repeat 
111 measurements $(n=33)$ of a large aliquot of dissolved sample from the splash zone of plate $12(10.4 d r i p s m i n-1$, $11235^{\circ} \mathrm{C}$ experiment). External errors ( $\pm 2 S D, \mathrm{n}=33$ ) range from $3.1 \%$ for $\mathrm{Sr}$ to $7.5 \%$ for $\mathrm{Cd}$. Concentrations of $\mathrm{Li}$ and $\mathrm{Na}$ were too low in the calcite samples for satisfactory measurements. Due to the difficulties in measuring these low concentrations, these elements are not discussed further in this work, although the complete set of measurements is included in the Supplementary Information Data Tables. To produce estimates of the surface area available for calcite precipitation, SEM images of seed crystals and of seed crystals with sample overgrowth were analysed with the image-processing package ImageJ (Rasband, 1997-2012). This image-analysis approach was taken because of the small quantities of calcite-growth in these cave-analogue conditions (7 to $66 \mathrm{mg}$ ), which are not conducive to BET analysis. ImageJ's particle-analysis tool was used to automate detection of the outlines of the crystals (figure Supplementary Information Figure 1) and to calculate the percentage coverage of the glass plate with crystal surfaces. To account for the three-dimensional nature of the growth surface, we multiplied by five the two-dimensional surface area derived by the ImageJ software. This assumes that, on average, the SEM imagery displays the tops of regular six-sided rhombohedral crystals, of which five sides are available for calcite precipitation. We do not establish or apply surface roughness to convert these 'edge' surface areas into total surface area values, and therefore the estimates obtained are minimum surface areas for which uncertainties are difficult to assess.

At each temperature, SEM images were taken from the centre of the splash zone and from the edge of the glass plate to account for the heterogeneous distribution of sample overgrowth (cf. SEM area in figure 1). These SEM images were taken of experiments covering the full range of sample masses and were used to define a relationship between crystal surface area and sample mass (Supplementary Information Figure 2). From a simple linear fit ( Supplementary Information Figure 2), this relationship was defined as:

$$
\text { surfacearea }\left(\mathrm{cm}^{2}\right)=0.89 \times \operatorname{samplemass}(\mathrm{mg})+6.67
$$

33 As each experiment proceeds, the surface area available for growth changes from that of the seed to that of the 34 seed with seven days worth of sample overgrowth. We applied half of the final sample mass for each experiment to equation 1 to obtain an average surface area that accounts for this evolving surface area. The estimated growth rates normalised for this surface area are displayed in Supplementary Information Figure 3. 
3.1. Mass, rate and distribution of calcite growth

139

The mass of calcite growth is variable with both drip rate and temperature. The daily, whole-plate mass of calcite growth increases with temperature, with an exponential curve of best fit for all drip rates of dailygrowthmass $=$ $1.4 e^{0.05[ \pm 0.001] T}$ (Day \& Henderson, 2011). Normalizing this growth mass to our estimated surface areas of crystal growth (cf. section 2.4) gives growth rates ranging from $1.2 \times 10^{-8} \mathrm{mmol} \times \mathrm{cm}^{-2} \times \mathrm{s}^{-1}$ (for the fast drip rate experiment at $7^{\circ} \mathrm{C}$ ) to $3.0 \times 10^{-8} \mathrm{mmol} \times \mathrm{cm}^{-2} \times \mathrm{s}^{-1}$ (for the medium drip rate experiment at $35^{\circ} \mathrm{C}$ ). These are maximum growth rates because the surface area estimates do not account for surface roughness. The proportion of Ca remaining in solution, $f$, calculated as $1-\frac{\text { massCa precipitated }}{\text { massdissolvedCaflowing overthe plate }}$, decreases systematically with temperature and increases systematically with drip rate according to the equations of best fit: $f=1 e^{-0.0016[ \pm 0.0002] T}$, $f=1 e^{-0.00038[ \pm 0.00002] T}$ and $f=1 e^{-0.00014[ \pm 0.000006] T}$ for the three drip rates 1.6, 5.8 and 10.4 drips $\times$ min $^{-1}$ respectively, for calcite precipitating within the splash zone (figure 6). The location and patterns of calcite precipitation on the glass plate are also variable with both drip rate and temperature (figure 2 ). At $7^{\circ} \mathrm{C}$, there is more calcite precipitation at the edges of the splash zone than in the centre (figure 2). This pattern of growth on the plates reverses at higher temperature, so there is more growth in the centre, where the drip impacts on the plate, than at the edges (cf. photographed glass plates " 1 " and "4" in figure 2).

\subsection{Trace-element to calcium ratios}

Results are described here for the three areas of each plate (figure 1) at each of three drip rates and four temperatures. Results are quoted as $D^{\prime}(X)=\frac{X / C a_{\text {solid }}^{f}}{X / C a_{\text {solution }}^{f I}}$, i.e. the trace-element to calcium ratio in the solid normalized by the trace-element to calcium ratio in the initial solution. The superscript $f$ denotes the proportion of the major element Ca remaining in solution. For $X / C a_{\text {solid }}^{f}, f$ is unknown (cf. section 4.1), whereas for $X / C a_{\text {solution }} f$ is equal to 1 in all cases as the measurements are made on the initial solution before any calcite precipitation. All values of $X / C a_{\text {solid }}^{f}$ and $X / C a_{\text {solution }}^{f=1}$ are tabulated in the Supplementary Information data tables.

$D^{\prime}(M g)$ varies between 0.012 and 0.029 (figure 3A). When considering the whole suite of data points, there are no systematic patterns or significant relationships between $D^{\prime}(M g)$ and temperature, drip rate or plate area. There is an increase of the average $D^{\prime}(M g)$ with temperature of $1.6 \%$ per degree Celsius, but when considering the spread of values caused by different drip rates and plate areas this increase is not statistically significant (figure 3).

$D^{\prime}(C o)$ varies between 1.22 and 1.83 and $D^{\prime}(B a)$ varies between 0.11 and 0.28 with neither showing a significant relationship with temperature, drip rate or sample area for the 18 data points at 25 and $35^{\circ} \mathrm{C}$. 
$D^{\prime}(S r)$ ranges from 0.12 to 0.30 , with no significant trends with temperature, drip rate or plate area (figure 3B). Two extreme values of $\sim 0.3$ occur for the $35^{\circ} \mathrm{C}$, slow drip rate experiments, with correspondingly high values for $D^{\prime}(B a)$ and $D^{\prime}(U)$.

$D^{\prime}(C d)$ varies between 3 and 37 with a systematic decrease in the average value with temperature of $4.1 \%$ per degree Celsius (figure 3C). There is a larger systematic increase in average $D^{\prime}(C d)$ with drip rate, an increase of $8.8 \%$ per $d r i p \times \min ^{-1}$ (Supplementary Information figure 4). There is no systematic relationship between $D^{\prime}(C d)$ and region of growth on the plate.

$D^{\prime}(U)$ varies between 0.06 and 1.43 with no significant relationship with temperature, drip rate or sample area (figure 3D). As for $\mathrm{Ba}$ and $\mathrm{Sr}$, there are significantly higher values for the $35^{\circ} \mathrm{C}$, slow drip rate experiment, which significantly increase the average $D^{\prime}(U)$ at this $35^{\circ} \mathrm{C}$ temperature.

In general there is a large degree of scatter in trace-element ratios between experiments given the similar and closely controlled growth conditions. Correlations between trace-element pairs are also generally weak (except for $\mathrm{Sr} / \mathrm{Ca}$ and $\mathrm{Ba} / \mathrm{Ca})$.

\section{Discussion}

\subsection{True partition coefficients $(D(X))$}

We cannot directly measure partition coefficients $D(X)$ at the point of mineral growth because $(X / C a)_{\text {solution }}^{f}$ values of individual sample areas (splash, flow and ponded zones) are unknown in the rapidly evolving chemical environment of carbonate growth on the plates. Instead we quote $D^{\prime}(X)=\frac{(X / C a)_{\text {solid }}^{f}}{(X / C a)_{\text {solution }}^{f=1}}$ based on measurements of the initial solution. For $D(X) \neq 1, D^{\prime}(X)=\frac{(X / C a)_{\text {solid }}^{f}}{(X / C a)_{\text {solution }}^{f=}}$ evolves away from $D(X)$ as calcite precipitation proceeds. For incompatible elements $(D(X)<1), D^{\prime}(X)$ increases as calcite precipitation proceeds, whereas for compatible elements $(D(X)>1), D^{\prime}(X)$ decreases as calcite precipitation proceeds. To provide the best estimate of $D(X)$ from $D^{\prime}(X)$ for a given temperature, we therefore select the smallest value of $D^{\prime}(X)$ for incompatible elements and the largest value of $D^{\prime}(X)$ for compatible elements, which identifies the solid formed from the least evolved solution in all cases. By comparing the mass of precipitated calcite to the total amount of $\mathrm{Ca}^{2+}$ flowing over the plate in solution during the experiment, the average depletion of calcium from solution is low (i.e. $<0.43 \%$ for the splash zone at all temperatures, Day \& Henderson, 2011), suggesting that $(X / C a)_{\text {solution }}^{f=1} \sim(X / C a)_{\text {solution }}^{f}$ for the least evolved cases that we select and therefore that $D^{\prime}(X)$ is a good estimate of $D(X)$. Although $D^{\prime}(C d)$ is likely to be a slight underestimate of $\mathrm{D}(\mathrm{Cd})$ because of the highly compatible nature of $\mathrm{Cd}$. 
These estimates of $D(X)$ allow the relationships between $D(X)$ and $T$ to be investigated whilst minimizing the scatter caused by variations in $f$ in $X / C a_{\text {solid }}$ data (figure 7). $\mathrm{D}(\mathrm{Mg})$ increases by $2 \%$ per degree Celsius, $\mathrm{D}(\mathrm{Cd})$ and $\mathrm{D}(\mathrm{U})$ decrease by 2.8 and $2.5 \%$ per degree Celsius respectively whereas $\mathrm{D}(\mathrm{Sr})$ does not change significantly with temperature for our experiments (figure 4 and table 2). For $\mathrm{D}(\mathrm{Sr})$, the lack of relationship with temperature that we observe is similar to that described by the experiments of Huang \& Fairchild (2001), although the individual values from the present study are higher than those of previous studies that had higher solution concentrations of $\mathrm{Na}$ (Lorens, 1981; Rimstidt et al., 1998; Huang \& Fairchild, 2001). Estimates of D(Mg) and D(Sr) from cave studies (Gascoyne, 1983; Huang et al., 2001; Johnson et al., 2006; Fairchild et al., 2010) are variable, even for those reported within the same cave system (figure 4). In some cases (Gascoyne, 1983; Huang et al., 2001; Fairchild et al., 2010) the measurement of $X / C a_{\text {solution }}$ (from modern drip-water) is not necessarily co-eval with $\mathrm{X} / \mathrm{Ca} a_{\text {solid }}$ (from the top 0.5 to several $\mathrm{mm}$ of stalagmite growth), with temporal changes in $X / C a_{\text {solution }}$ potentially explaining variability in estimated $D(X)$ within the same cave system. Some of this variability in the estimates from natural caves may also be explained by the concept of mixing (section 4.4). There are no published values of $\mathrm{D}(\mathrm{Co})$ or $\mathrm{D}(\mathrm{Cd})$ from cave studies to compare with these laboratory growth values but the results from the beaker-type experiments of Lorens (1981) of $\mathrm{D}(\mathrm{Co})=4.5$ and $\mathrm{D}(\mathrm{Cd})=26.7$ at $25^{\circ} \mathrm{C}$ are both higher than the corresponding results from our study (1.8 and 20 respectively).

\subsection{Temperature control on trace-element incorporation}

For palaeoclimate reconstruction we are interested in how change in temperature affects $\mathrm{X} / \mathrm{Ca}$ solid so that speleothem $\mathrm{X} / \mathrm{Ca} a_{\text {solid }}$ can be used to derive past temperature. Temperature affects the chemistry involved in stalagmite precipitation in multiple ways. As temperature increases, in addition to increased thermal energy, the rate of $\mathrm{CO}_{2}$ degassing and calcite-precipitation both increase (Day \& Henderson, 2011; Dreybrodt, 2012); the system evolves towards greater levels of calcium depletion from solution ( $f$ decreases); and the evolution of the solution saturation index for calcite $\left(S I_{c c}\right)$ from its initial value of 0.34 increases to higher values (Reynard et al., 2011; Dreybrodt, 2012; Day \& Henderson, 2012).

Our experiments demonstrate much smaller changes in $D(X)$ with temperature than for marine organic calcite. For example Lea et al. (1999) and Mashiotta et al. (1999) observed a 10\% increase in D(Mg) per degree Celsius from laboratory culturing of specific planktonic foraminifera species, as compared with a $2 \%$ increase for our inorganic cave-analogue experiments. From box-core measurements for G. bulloides, Rickaby \& Elderfield (1999) see an increase in Cd incorporation of $15 \%$ per degree Celsius, whereas we observe a $2.8 \%$ decrease per degree Celsius.

This very different incorporation behaviour for marine organic calcite is likely to be driven by changes in the 
ionic strength of the growth medium and, particularly, by biological processes involved in biomineralization. This demonstrates the importance of using partition coefficients that relate to the growth conditions of interest.

We briefly discuss comparison of the relationship between $D(X)$ and $T$ from this study with predictions based on thermodynamic considerations, based in particular on the following definition of D

$$
D=\left(\frac{K_{\mathrm{CaCO}_{3}}}{K_{X_{\nu} \mathrm{CO}_{3}}}\right)^{\frac{1}{v}}\left(\frac{\gamma_{X}}{\gamma_{\mathrm{Ca}}}\right) \exp \left(\frac{-\Delta \mu}{R T}\right)
$$

from McIntire (1963), which we consider here only for the precipitation of calcite. $K_{X_{\nu} C O_{3}}$ is the solubility product constant of calcite or of the metal carbonate $\mathrm{X}_{\nu} \mathrm{CO}_{3}, v$ is the number of cations in $\mathrm{X}_{\nu} \mathrm{CO}_{3}, \gamma$ denotes activity coefficients of the elements in the aqueous solution, $R$ is the universal gas constant, $T$ is the temperature in Kelvin and $\Delta \mu$ is a measure of the deviation of the actual solid solution from ideality. The partition coefficient $D$ is therefore defined as the product of three factors: (1) the ratio of the solubility product constants of the two end member solids (calcite and $\mathrm{X}_{v} \mathrm{CO}_{3}$ ); (2) a 'solution interaction factor' based on the activity coefficients of the aqueous cations; and (3) a 'solid interaction factor' which takes account of chemical potentials within the solid solution (McIntire, 1963). McIntire (1963) suggests that for ideal solid solutions, the first factor is the only significant one with the other two factors approaching 1.0, but that ideal solid solutions are likely only for cations with similar properties as $\mathrm{Ca}^{2+}$. Hence the relative solubility of calcite and $\mathrm{X}_{v} \mathrm{CO}_{3}$ are important for defining $D(X)$ of ideal solid solutions. The PHREEQC program (Parkhurst \& Appelo, 1999) indicates that the solution interaction factor $\left(\frac{\gamma_{X}}{\gamma_{C a}}\right) \sim 1.0$. The solid interaction factor $\left(\exp \left(\frac{-\Delta \mu}{R T}\right)\right)$ is therefore significantly different from 1.0 as indicated by our value of $D(X)$ which is not equal to $\left(\frac{K_{\mathrm{CaCO}_{3}}}{K_{X_{V} \mathrm{CO}_{3}}}\right)^{\frac{1}{v}}$, as is expected in these dynamic growth conditions.

The relationship shown in equation 2 is used by Rimstidt et al. (1998) to link measurements of $D(X)$ from natural and laboratory samples and to make predictions of $D(X)$ for elements and temperatures for which there are no measurements. Selecting values of $D(X)$ most distinct from 1.0 from a wide range of published studies, these authors defined two equations $\left(K_{d}^{\prime}=1.6\left(\frac{K_{X C O_{3}}}{K_{T_{r C O}}}\right)^{0.57}\right.$ and $K_{d}^{\prime}=0.022\left(\frac{K_{X C O_{3}}}{K_{T_{r C O}}}\right)^{0.57}$ ) for the relationship between measured partition coefficients and solubility product constants, with the first and second equations relating to elements forming rhombohedral and orthorhombic carbonates respectively. Published values of $K_{X_{\nu} \mathrm{CO}_{3}}$ as a function of $T$ were used to estimate values of $D(X)$ as a function of $T$ (Rimstidt et al., 1998). A comparison of results from our study with predicted values by Rimstidt et al. (1998) are collated in table 2. Individual values of $D(X)$ from our study are typically closer to unity than those of Rimstidt et al. (1998) (table 2). There are likely to be two reasons for this: i) the deliberate selection by Rimstidt et al. (1998) of $D(X)$ values from the lowest growth rate 
studies and ii) differences in the specific growth conditions between our study and those selected by Rimstidt et al. (1998), which were dominated by marine-type growth conditions. In the case of (ii), we know for example, that the higher $\left[\mathrm{Na}^{+}\right]$of marine solutions is likely to depress $\mathrm{D}(\mathrm{Sr})$ to lower values. There is, however, reasonable agreement between the measured relationships between $D(X)$ and $T$ established by this study and those predicted by Rimstidt et al. (1998) based on considerations of a solubility control on $D(X)$.

Overall there is a varied response of trace-element incorporation to temperature with $D(X)$ increasing with $T$ for $\mathrm{Mg}$, decreasing with $\mathrm{T}$ for $\mathrm{Cd}$ and remaining constant for $\mathrm{Sr}$, with reasonable agreement in all cases with predictions based on the change of solubility constants between calcite and $\mathrm{X}_{\nu} \mathrm{CO}_{3}$ (McIntire, 1963; Rimstidt et al., 1998; Curti, 1999a). This supports the theoretical understanding of the mechanisms of trace-element incorporation and suggests that chemical processes on the stalagmite surface follow basic chemical principles, which can lead to a more rigorous, quantitative interpretation of speleothem trace-element measurements.

\subsection{Relative importance of $T$ and $f$ in controlling $X / C a$}

To assess whether our constraints on $D(X)$ can help with interpretation of varying $X / C a$ ratios in stalagmites to reconstruct past environmental conditions we consider a Rayleigh distillation model for the evolution of $X / C a_{\text {solid }(\text { solution) }}$ in the unsaturated zone and in the cave environment. The model considers a reservoir of solution with dissolved calcium, DIC and trace-elements, and a calcite product, which precipitates from the solution, depleting elements from the reservoir. There is conservation of mass between these two phases so, for instance, $[\mathrm{Ca}]_{\text {solution }}+[\mathrm{Ca}]_{\text {calcite }}=$ constant . The instantaneous trace-element to calcium ratio of the product is given by:

$$
X / C a_{\text {solid }}^{f}=X / C a_{\text {solution }}^{f=1} \times D(X) \times f^{(D(X)-1)}
$$

where $f$ is the proportion of Ca remaining in solution. In natural caves, $f$ evolves to lower values either because of the well-established concept of prior calcite precipitation before the solution reaches the stalagmite surface (e.g Fairchild et al., 2000; McMillan et al., 2005; Johnson et al., 2006; Sherwin \& Baldini, 2011) or because decreased drip rate leads to increased precipitation on the stalagmite surface (figure 6A; Dreybrodt, 2012; Day \& Henderson, 2012). The cumulative trace-element to calcium ratio of the calcite product is given by the integrated form of equation 3, i.e. $X / C a_{\text {solid }}^{f}=X / C a_{\text {solution }}^{f=1} \frac{f^{D}-1}{f-1}$ (Zeebe \& Wolf-Gladrow, 2005). Further, we use the relationship between $D(X)$ and T, in the form $D(X)=A e^{b T}$, to introduce temperature into equation 3, which becomes:

$$
X / C a_{\text {solid }}^{f}=X / C a_{\text {solution }}^{f=1} \times A e^{b T} \times f^{\left(A e^{b T}-1\right)}
$$


For a constant drip-water chemistry, $T$ and $f$ are the two variables that control stalagmite chemistry and both are closely attributable to climate. Calculated $\mathrm{X} / \mathrm{Ca} a_{\text {speleothem }}^{f}$ values, based on equation 4 are illustrated in figure 5 for typical ranges observed in natural settings with temperatures between 5 and $35^{\circ} \mathrm{C}$ and $f$ between 1 and 0.7 . Values of the constants in equation 4 (' $A$ ' and ' $b$ ') are defined by the measurements from this study (table 2), with $X / C a_{\text {solution }}^{f=1}$ also taken from this study, itself based on natural cave measurements (table 1$)$. Where contours are horizontal in figure 5, $T$ is the dominant control on trace-element incorporation, whereas where contours are vertical, $f$ is the dominant control. This figure suggests that, for typical caves, $f$ is the dominant control on $X / C a_{\text {speleothem }}$ for $\mathrm{Sr}, \mathrm{Co}$ and $\mathrm{Cd}$. For $\mathrm{Mg}$, the difference between the effect of $f$ and $T$ is less significant, although over short timescales in caves that buffer temperature effectively, $\mathrm{Mg} / \mathrm{Ca}$ changes are more likely to result from changes in $f$ (figure 5).

This analysis has ignored possible variation in dripwater chemistry, which is expected in most cave settings but which cannot be measured for the past. Analysis of equation 4, however, allows an assessment of whether multiple elements are responding to a common, significant change in $f$ or instead to individual variations in $X / C a_{\text {solution }}^{f=1}$. Figure 6 summarizes expected changes in $X / C a_{\text {stalagmite }}$ for changes in $f$. As an example, this figure illustrates that for a change in $\mathrm{Mg} / \mathrm{Ca}$ of $3.7 \%, \mathrm{Cd} / \mathrm{Ca}$ would change by $44.4 \%$, for $f$ changing from 0.99 to 0.96 , if $T$ and dripwater chemistry remained unchanged. Considering trends in multiple trace-elements in this way may help to distinguish between changes in $f$ (caused for example by changes in drip rate within the cave) and changes in drip-water chemistry (caused for example by changes in weathering, by changes in dust supply to the soil zone or by changes in hydrological factors).

Compatible elements, such as $\mathrm{Cd}$, provide additional information on $f$. For high $\mathrm{D}(\mathrm{Cd}), \mathrm{Cd}$ is rapidly depleted from solution so high $C d / C a_{\text {stalagmite }}$ values are are likely to correspond to periods of high $f$ accompanied by smaller but predictable changes in other elements (e.g. to lower $\mathrm{Mg} / \mathrm{Ca}$ and $\mathrm{Sr} / \mathrm{Ca}$ ). It might be possible to extend this logic of using $C d / C a_{\text {solid }}$ to estimate boundary values of $f$ by investigating other compatible elements with values of $D(X)$ between that of $\mathrm{Cd}$ and unity. $\mathrm{Co}, \mathrm{Zn}$ and $\mathrm{Cu}$ are examples of elements which might be appropriate (Kitano et al., 1968; Curti, 1999b), although hydrological and colloidal controls of these elements need to be considered (Borsato et al., 2007; Hartland et al., 2012) in case variability in the drip-solution composition outweighs the response of these elements to $f$ on the growth surface.

\subsection{Patterns of calcite growth and mixing effects on trace-element ratios}

Having previously selected the least-evolved calcite precipitates to define $\mathrm{D}(\mathrm{X})$ (section 4.1), we now consider the whole data set (nine measurements at each temperature, for three drip rates and three sample areas) to investigate 
processes taking place on the growth surface. Many of these $X / C a_{\text {solid }}$ measurements do not fall on or between instantaneous or cumulative Rayleigh fractionation curves as might be expected (figure 7). All samples are grown on the same seed substrate and at each temperature, the nine solid samples are grown simultaneously, in identical conditions with drip rate and sample area as the only varying factors. Despite significant differences between values of $D^{\prime}(X)$, there is no significant relationship between $D^{\prime}(X)$ and drip rate (Supplementary Information figure 4) or between $D^{\prime}(X)$ and sample area (Supplementary Information figure 5). It is therefore a combination of drip rate and sample location which explains these deviations from the Rayleigh fractionation curves. This is consistent with mixing of two forms: i) solution mixing between the solution layer and the impinging drip solution (Muhlinghaus et al., 2007, 2009; Deininger et al., 2012), and ii) mixing between solids formed from solutions with different $f$. Solution mixing in its simplest form occurs on the growth axis, where the solution layer, evolving towards lower values of $f$ (i.e. more Ca precipitated from solution), mixes with the less-evolved impinging drop (Muhlinghaus et al., 2007, 2009; Deininger et al., 2012).

To understand the mixing between solids in these experiments requires consideration of patterns of growth on the glass plate. At $7^{\circ} \mathrm{C}$, there is more calcite precipitation at the edges of the splash zone than in the centre (figure 2). At the centre of the plate the saturation is too low to precipitate much calcite and the solution residence time is too short to allow sufficient $\mathrm{CO}_{2}$-degassing and subsequent saturation-increase for significant calcite precipitation to occur (Dreybrodt, 2012). As the drip impacts on the plate, however, it breaks up into micro-droplets, some of which are supplied directly to the outer reaches of the plate, the 'splash effect', (Muhlinghaus et al., 2007, 2009; Day \& Henderson, 2012; Deininger et al., 2012). These micro-droplets are not displaced with every drip and the increased residence time of these droplets allows for calcite growth and consequently greater depletion of $\mathrm{Ca}$ from the solution (i.e. lower $f$ ) (Day \& Henderson, 2012). Away from the area of drip impact there is also likely to be mixing between solution that flows down the plate (evolving to lower $f$ ) with micro-droplets of unevolved solution supplied directly to the outer reaches of the plate. Different regions of the plate therefore have calcite growth at different points of evolution along Rayleigh fractionation curves (i.e. with different $f$ ).

These two effects, solution mixing and the variable extent of calcite growth on the same glass plate, mean that mixing becomes an important process for trace-element ratios. For decreasing $f$ at a given set of growth conditions, solutions and solids are expected to evolve along Rayleigh fractionation curves, but mixtures of solutions with different $f$ or mixtures of precipitates from different areas will be located on mixing lines between points on the Rayleigh curve. The most extreme form of mixing involves mixtures of solids or solutions with $f$ approaching 0 and 1 . This case defines the maximum degree to which mixing lines deviate from the Rayleigh fractionation curves (figure 8) and therefore forms the boundary mixing line. An infinite number of other mixing lines exist 
within the area between this boundary mixing line and the Rayleigh curves (figure 8).

These mixing effects, between different points along the Rayleigh fractionation curve, can also be observed in comparison of one trace-element with another (figure 9). This approach requires no knowledge of $f$, it therefore removes the complexity of spatial variations in $f$ and is more applicable to past speleothem growth where $f$ is unknown. In all but two of the 36 experimental calcites, paired values of $D^{\prime}(X)$ lie between the instantaneous fractionation curve and the boundary mixing line, suggesting that in all of those cases Rayleigh fractionation and some degree of mixing can explain the variations in $\mathrm{X} / \mathrm{Ca}_{\text {solid }}$. That these two processes both operate to control $\mathrm{X} / \mathrm{Ca}$ ratios on the growing surface explains the scatter in $\mathrm{X} / \mathrm{Ca}$ observed during these experiments and may also help to explain some of the variability in partition coefficients measured in natural caves (figure 4). This is particularly true for $\mathrm{Mg}$, where variations in $f$ and mixing could explain most or all of the variation in $D(M g)$ estimates from natural caves (figure 4). Some $D(S r)$ estimates from natural caves are lower than $D(S r)$ from the present experiments, suggesting that, for Sr, there are additional controls, other than $f$ and mixing, that explain the variability in $\mathrm{D}(\mathrm{Sr})$ in these cases. The variety of $X / \mathrm{Ca}$ observed between experiments does not require a variable value of $D(X)$, and the lack of correlation between one trace-element and another is also well explained. Where two trace-elements have very different $D(X)$ values (e.g. $\mathrm{Cd}$ and $\mathrm{Mg}$ ), the effect of mixing does not allow for linear correlation between two elements and increases the area of scatter in these two-element plots (figure 9). Where $D(X)$ values are similar, however, (e.g. Sr and Ba) mixing lines are approximately parallel to Rayleigh fractionation curves and resulting $\mathrm{Sr} / \mathrm{Ca}$ and $\mathrm{Ba} / \mathrm{Ca}$ ratios correlate in grown calcite (figure 9). This observation may explain the tendency for $\mathrm{Sr}$ and $\mathrm{Ba}$ to correlate with one another in many stalagmite samples, while many other trace-element pairs do not.

These observations, made possible by the controlled-nature of the experiments, support the importance of mixing recognized by recent modelling work (Muhlinghaus et al., 2007, 2009), and further demonstrate the significance of mixing in the interpretation of stalagmite records. Solution mixing occurs for stalagmites forming under all but the slowest of drips. Mixing coefficients are closely related to drip rate (Muhlinghaus et al., 2007), are predicted to impact on $\delta^{18} O_{\text {stalagmite }}$ (Muhlinghaus et al., 2009; Deininger et al., 2012) and also to cause significant shifts in $\delta^{13} C_{\text {stalagmite }}$ (Muhlinghaus et al., 2007). Within a multi-proxy approach to interpreting stalagmite records, elements such as $\mathrm{Cd}$ that are sensitive to solution mixing may therefore help to reconstruct changes in drip intervals and mixing coefficients. The mixing of solids observed in these experiments is a feature of our sample areas (figure 1) incorporating calcite precipitating from solutions with different $f$. This mixing has a negligible effect on the definition of our partition coefficients (section 4.1) because the effect of mixing is minimal for the $f$ values used to calculate partition coefficients ( $f=1$ to 0.996 , section 4.1 ), with the maximum effect at $f=0.996$ calculated 
to be well within our error estimates for all values of $D(X)$ (table 3). In future work, very localized sampling of cave-analogue calcite may remove the effect of solid mixing and may therefore help to quantify the effect of solution mixing at different drip intervals. For natural stalagmites, the mixing between solids will be reduced for calcite sampled along the growth axis, but mixing between solids with different $f$ will still occur if the sampling resolution is lower than the time interval of change of the mixing factors (e.g. drip rate). High-resolution sampling along the growth axis and careful selection of sample material, combined with cross-plotting between elements and alongside Rayleigh curves will reduce the effect of solid mixing and may help with the interpretation of stalagmite trace-element ratios.

\subsection{Growth rate and controls on $\mathrm{D}(\mathrm{Sr})$}

Previous studies (Lorens, 1981; Tesoriero \& Pankow, 1996) have suggested precipitation rate as an important factor controlling $\mathrm{D}(\mathrm{Sr})$ during calcite growth and this growth-rate control has sometimes been assumed in stalagmite studies (e.g. Couchoud, 2008; Hopley et al., 2009). However, the increase in D(Sr) reported by Lorens (1981) and Tesoriero \& Pankow (1996), from marine-analogue experiments, occurs over considerable changes in growth rate (from c. 0.03 to $34 \times 10^{-8} \mathrm{mmol} \times \mathrm{cm}^{-2} \times \mathrm{s}^{-1}$ for Lorens, 1981 and from c. 0.7 to c. $118 \times 10^{-8} \mathrm{mmol} \times \mathrm{cm}^{-2} \times \mathrm{s}^{-1}$ for Tesoriero \& Pankow, 1996). Whilst most calcite saturation indices ( growth rates) can be produced for laboratory beaker experiments (e.g. by mixing increasing concentrations of $\mathrm{CaCl}_{2}$ and $\mathrm{NaHCO}_{3}$ in solution) the same is not true for natural speleothem growth. An important question is therefore whether $\mathrm{D}(\mathrm{Sr})$ will respond to changes in growth rates within the range applicable to natural speleothems.

We see no change in $\mathrm{D}(\mathrm{Sr})$ over the eightfold-increase in growth rate (from $0.97 \mathrm{mg} /$ day to $7.70 \mathrm{mg} /$ day) as temperature increases from 7 to $35^{\circ} \mathrm{C}$, corresponding to an increase in growth rate normalized to surface area of 1.2 to $3.0 \times 10^{-8} \mathrm{mmol} \times \mathrm{cm}^{-2} \times \mathrm{s}^{-1}$ (figure 4). This absence of change in $\mathrm{D}(\mathrm{Sr})$ is consistent with Lorens (1981) and Tesoriero \& Pankow (1996), who did not observe significant changes in $D(S r)$ over comparable changes in growth rate. These cave-analogue results therefore suggest that for stalagmite-type growth conditions growth rate does not exert a significant effect on Sr-incorporation.

We also briefly consider measured $\mathrm{D}(\mathrm{Sr}$ ) from natural caves (figure 4), ranging from 0.08 to 0.3 (Gascoyne, 1983; Huang et al., 2001; Johnson et al., 2006; Fairchild et al., 2010). For Obir cave, the detailed measurements of Fairchild et al., 2010 demonstrate a significant range of $\mathrm{D}(\mathrm{Sr})$ (0.08 to 0.13) for three samples of modernday stalagmite growth, despite a small range of estimated growth rates $\left(0.24\right.$ to $0.45 \times 10^{-8} \mathrm{mmol} \times \mathrm{cm}^{-2} \times \mathrm{s}^{-1}$ calculated using PHREEQC (Parkhurst \& Appelo, 1999), Fairchild et al., 2010 solution-chemistry measurements 
and (Baker et al., 1998) equations relating solution chemistry to growth rate). Overall, this suggests that factors other than growth rate are exerting a significant effect on $\mathrm{D}(\mathrm{Sr})$.

\section{Conclusions}

Trace-element partition coefficients $(D(M g), D(C o), D(S r), D(C d), D(B a), D(U))$ measured in controlled, caveanalogue conditions, from minimally-evolved solutions $(1>f>0.996)$ demonstrate a varied response of traceelement incorporation to temperature, with $D(X)$ increasing with $T$ for $\mathrm{Mg}$, decreasing with $T$ for $\mathrm{Cd}$ and remaining constant for $\mathrm{Sr}$, with reasonable agreement in all cases with predictions based on the change of solubility constants between calcite and $\mathrm{X}_{v} \mathrm{CO}_{3}$ (McIntire, 1963; Rimstidt et al., 1998; Curti, 1999b).

Applying these partition coefficients to a Rayleigh fractionation model of evolving $X / C a_{\text {speleothem }}$ suggests that $f$ (i.e. the fraction of Ca remaining in solution) is the dominant control on $\mathrm{X} / \mathrm{Ca} \mathrm{a}_{\text {speleothem }}$. Compatible elements such as $\mathrm{Cd}$ are shown to be particularly sensitive to changes in $f$ (including prior calcite precipitation), with high $\mathrm{Cd} / \mathrm{C} \mathrm{a}_{\text {stalagmite }}$ indicative of low amounts of prior calcite precipitation. Combining various trace-elements may allow past changes in calcite precipitation extent or temperature to be assessed in natural samples.

There is no change in $D(S r)$ as temperature increases from 7 to $35^{\circ} \mathrm{C}$ despite a 2.5 times increase in surface area normalised growth rate, therefore changes in growth rate by less then a factor of 2.5 are unlikely to lead to changes

in $D(S r)$ in caves. Future cave-analogue experiments could usefully examine other variables (e.g. drip solution

$\left.S I_{\text {calcite }}\right)$ to further investigate the relationship between growth rate and trace-element incorporation in speleothem calcite.

The full suite of measurements from these experiments demonstrates deviations of $\mathrm{X} / \mathrm{C} a_{\text {solid }}$ from predicted Rayleigh curves. Mixing of both solids and solutions at different stages of precipitation can explain these deviations and should be considered when analysing trace-elements for palaeo-environmental reconstruction. This may help to explain variable $D(X)$ measured in natural caves and may help, as part of a multi-proxy approach, to establish the effect of mixing on other measurements such as $\delta^{13} C_{\text {stalagmite }}$ and $\delta^{18} O_{\text {stalagmite }}$.

\section{Acknowledgements}

This work was supported by the Gary Comer Abrupt Climate Change Fellowship and NERC grant NE/G003416/1. We thank Prof. Ian Fairchild and two anonymous reviewers for their contribution to an improved manuscript and Prof. Frank McDermott for his editorial handling of this work. 
Albarède, F. 2003. Geochemistry An Introduction. Cambridge University Press. 25

Baker, A., \& Genty, D. 1999. Fluorescence wavelength and intensity variations of cave waters. Journal of Hydrology, 217(1), 19-34. 3

Baker, A., Genty, D., Dreybrodt, W., Barnes, W.L., Mockler, N.J., \& Grapes, J. 1998. Testing theoretically predicted stalagmite growth rate with recent annually laminated samples: Implications for past stalagmite deposition. Geochimica et Cosmochimica Acta, 62(13), 2405-2405. 5, 17, 25

Bastin, B. 1978. L'analyse pollinique des stalagmites: Une nouvelle possibilité d'approche des fluctuations climatiques du quaternaire. Annales de la Societé Geologique de Belgue, 101, 13-19. 3

Borsato, A, Frisia, S, Fairchild, IJ, Somogyi, A, \& Susini, J. 2007. Trace element distribution in annual stalagmite laminae mapped by micrometer-resolution X-ray fluorescence: Implications for incorporation of environmentally significant species. Geochimica Et Cosmochimica Acta, 71(6), 1494-1512. 13

Burns, S.J., Fleitmann, D., Matter, A., Neff, U., \& Mangini, A. 2001. Speleothem evidence from Oman for continental pluvial events during interglacial periods. Geology, 29(7), 623-626. 3

Camacho, C Navarro, Carrión, JS, Navarro, J, Munuera, M, \& Prieto, AR. 2000. An experimental approach to the palynology of cave deposits. Journal of Quaternary Science, 15(6), 603-619. 3

Couchoud, I. 2008. Speleothems as archives of paleoenvironmental change [Les spéléothèmes, archives des variations paléoenvironnementales]. Quaternaire, 19(4), 255-274. 16

Curti, E. 1999a. Coprecipitation of radionuclides with calcite: estimation of partition coefficients based on a review of laboratory investigations and geochemical data. Applied Geochemistry, 14(4), 433-445. 12

Curti, E. 1999b. Coprecipitation of radionuclides with calcite: estimation of partition coefficients based on a review of laboratory investigations and geochemical data. Applied Geochemistry, 14(4), 433-445. 13, 17

Day, C.C., \& Henderson, G.M. 2011. Oxygen isotopes in calcite grown under cave-analogue conditions. Geochimica et Cosmochimica Acta, 75, 3956-3972. 4, 5, 6, 8, 9, 10

Day, C.C., \& Henderson, G.M. 2012. Response to the Comment by W. Dreybrodt on "Oxygen isotopes in calcite grown under cave-analogue conditions". Geochimica et Cosmochimica Acta, 85, 388-389. 10, 12, 14 
Deininger, M., Fohlmeister, J., Scholz, D., \& Mangini, A. 2012. Isotope disequilibrium effects: the influence of evaporation and ventilation effects on the carbon and oxygen isotope composition of speleothems-a model approach. Geochimica et Cosmochimica Acta. 14, 15

Dorale, J.A., González, L.A., Reagan, M.K., Pickett, D.A., Murrell, M.T., \& Baker, R.G. 1992. A high-resolution record of holocene climate change in speleothem calcite from cold water cave, northeast iowa. Science (New York, NY), 258(5088), 1626. 3

Dreybrodt, W. 2012. Comment on "Oxygen isotopes in calcite grown under cave-analogue conditions" by C.C. Day and G.M. Henderson. Geochimica et Cosmochimica Acta, 85, 383-387. 10, 12, 14

Fairchild, I.J., Borsato, A., Tooth, A.F., Frisia, S., Hawkesworth, C.J., Huang, Y.M., McDermott, F., \& Spiro, B. 2000. Controls on trace element ( $\mathrm{Sr}-\mathrm{Mg}$ ) compositions of carbonate cave waters: implications for speleothem climatic records. Chemical Geology, 166(3-4), 255-269. 12

Fairchild, I.J., Spötl, C., Frisia, S., Borsato, A., Susini, J., Wynn, P.M., Cauzid, J., et al. 2010. Petrology and geochemistry of annually laminated stalagmites from an Alpine cave (Obir, Austria): seasonal cave physiology. Geological Society, London, Special Publications, 336(1), 295-321. 10, 16

Frisia, S., Borsato, A., Fairchild, I.J., McDermott, F., \& Selmo, E.M. 2002. Aragonite-calcite relationships in speleothems (Grotte de Clamouse, France): environment, fabrics, and carbonate geochemistry. Journal of Sedimentary Research, 72(5), 687-699. 3

Gascoyne, M. 1983. Trace-element partition-coefficients in the calcite water-system and their paleoclimatic significance in cave studies. Journal of Hydrology, 61(1-3), 213-222. 3, 4, 10, 16

Genty, D., Blamart, D., Ghaleb, B., Plagnes, V., Causse, Ch., Bakalowicz, M., Zouari, K., Chkir, N., Hellstrom, J., Wainer, K., \& Bourges, F. 2006. Timing and dynamics of the last deglaciation from European and North African $\delta^{13} C$ stalagmite profiles - comparison with Chinese and South Hemisphere stalagmites. Quaternary Science Reviews, 25(17-18), 2118-2142. 3

Hartland, A., Fairchild, I.J., Lead, J.R., Borsato, A., Baker, A., Frisia, S., \& Baalousha, M. 2012. From soil to cave: Transport of trace metals by natural organic matter in karst dripwaters. Chemical Geology, 304-305, $68-82.13$

Hendy, C.H. 1971. Isotopic geochemistry of speleothems-I. calculations of effects of difference modes of formation on isotopic composition of speleothems and their applicability as palaeoclimatic indicators. Geochimica Et Cosmochimica Acta, 35(8), 801-824. 3 
Hopley, P.J., Marshall, J.D., \& Latham, A.G. 2009. Speleothem preservation and diagenesis in South African hominin sites: Implications for paleoenvironments and geochronology. Geoarchaeology, 24(5), 519-547. 16

Huang, Y., Fairchild, I.J., Borsato, A., Frisia, S., Cassidy, N.J., McDermott, F., \& Hawkesworth, C.J. 2001. Seasonal variations in $\mathrm{Sr}, \mathrm{Mg}$ and $\mathrm{P}$ in modern speleothems (Grotta di Ernesto, Italy). Chemical Geology, 175(3-4), 429-448. 3, 10, 16

Huang, Y.M., \& Fairchild, I.J. 2001. Partitioning of $\mathrm{Sr}^{2+}$ and $\mathrm{Mg}^{2+}$ into calcite under karst-analogue experimental conditions. Geochimica et Cosmochimica Acta, 65(1), 47-62. 3, 4, 10

Ishii, S.K.L., \& Boyer, T.H. 2012. Behavior of Reoccuring PARAFAC Components in Fluorescent Dissolved Organd Matter in Natural and Engineered Systems: A Critical Review. Environmental Sience and Technology, 46, 2006-2017. 3

Johnson, K.R., Hu, C.Y., Belshaw, N.S., \& Henderson, G.M. 2006. Seasonal trace-element and stable-isotope variations in a Chinese speleothem: The potential for high-resolution paleomonsoon reconstruction. Earth and Planetary Science Letters, 244(1-2), 394-407. 3, 10, 12, 16, 25

Kitano, Y., Tokuyama, A., \& Kanamori, N. 1968. Measurement of the distribution coefficient of zinc and copper between carbonate precipitate and solution. J. Earth Sciences - Nagoya Univ., 16. 13

Lauritzen, S.E. 1995. High-resolution paleotemperature proxy record for the last interglaciation based on Norwegian speleothems. Quaternary Research, 43(2), 133-146. 3

Lea, D.W., \& Martin, P.A. 1996. A rapid mass spectrometric method for the simultaneous analysis of barium, cadmium, and strontium in foraminifera shells. Geochimica et Cosmochimica Acta, 60(16), 3143-3149. 6

Lea, D.W., Mashiotta, T.A., \& Spero, H.J. 1999. Controls on magnesium and strontium uptake in planktonic foraminifera determined by live culturing. Geochimica et Cosmochimica Acta, 63(16), 2369-2379. 10

Lin, Y.-P., Singer P.C. 2005. Effects of seed material and solution composition on calcite precipitation. Geochimica et Cosmochimica Acta, 69(18), 4495-4504. 5

Lorens, R.B. 1981. Sr, Cd, Mn and Co distribution coefficients in calcite as a function of calcite precipitation rate. Geochimica et Cosmochimica Acta, 45(4), 553-561. 10, 16

Mashiotta, T.A., Lea, D.W., \& Spero, H.J. 1999. Glacial-interglacial changes in Subantarctic sea surface temperature and $\delta^{18} \mathrm{O}$-water using foraminiferal Mg. Earth and Planetary Science Letters, 170(4), 417-432. 10 
McDermott, F., Atkinson, T.C., Fairchild, I.J., Baldini, L.M., \& Mattey, D.P. 2011. A first evaluation of the spatial gradients in $\delta^{18} \mathrm{O}$ recorded by European Holocene speleothems. Global and Planetary Change, 79(3), 275-287. 3

McIntire, W.L. 1963. Trace element partition coefficients: a review of theory and applications to geology. Geochimica et Cosmochimica Acta, 27(December), 1209-1264. 11, 12, 17

McMillan, E.A., Fairchild, I.J., Frisia, S., Borsato, A., \& McDermott, F. 2005. Annual trace element cycles in calcite-aragonite speleothems: evidence of drought in the western Mediterranean 1200-1100 yr BP. Journal of Quaternary Science, 20(5), 423-433. 12

Meyer, M.C., Spötl, C., Mangini, A., \& Tessadri, R. 2012. Speleothem deposition at the glaciation threshold An attempt to constrain the age and paleoenvironmental significance of a detrital-rich flowstone sequence from Entrische Kirche Cave (Austria). Palaeogeography Palaeoclimatology Palaeoecology,319(Feb.), 93-106. 3

Morse, J.W., \& Bender, M.L. 1990. Partition-coefficients in calcite: examinations of factors influencing the validity of experimental results and their application to natural systems. Chemical Geology, 82(3-4), 265-277. 3,4

Motyka, J., Gradzinski, M., Bella, P., \& Holubek, P. 2005. Chemistry of waters from selected caves on Slovakia a reconnaissance study. Environmental Geology, 48(6), 682-692. 25

Muhlinghaus, C., Scholz, D., \& Mangini, A. 2007. Modelling stalagmite growth and $\delta^{13}$ C as a function of drip interval and temperature. Geochimica et Cosmochimica Acta, 71(11), 2780-2790. 14, 15

Muhlinghaus, C., Scholz, D., \& Mangini, A. 2009. Modelling fractionation of stable isotopes in stalagmites. Geochimica et Cosmochimica Acta, 73(24), 7275-7289. 14, 15

Orland, I.J., Bar-Matthews, M., Ayalon, A., Matthews, A., Kozdon, R., Ushikubo, T., \& Valley, J.W. 2012. Seasonal resolution of Eastern Mediterranean climate change since $34 \mathrm{ka}$ from a Soreq Cave speleothem. Geochimica et Cosmochimica Acta. 3

Paquette, J., \& Reeder, R.J. 1995. Relationship between surface-structure, growth-mechanism, and trace-element incorporation in calcite. Geochimica et Cosmochimica Acta, 59(4), 735-749. 4

Parkhurst, D.L., \& Appelo, C.A.J. 1999. User's guide to PHREEQC (version 2): a computer program for speciation, batch-reaction, one-dimensional transport, and inverse geochemical calculations. Vol. 99-4259. Denver, Colo.: U.S. Department of the Interior, U.S. Geological Survey. 6, 11, 16 
Pingitore, N.E., \& Eastman, M.P. 1986. The coprecipitation of $\mathrm{Sr}^{2+}$ with calcite at $25^{\circ} \mathrm{C}$ and 1 atm. Geochimica et Cosmochimica Acta, 50(10), 2195-2203. 3, 4

Railsback, L.B., Brook, G.A., Chen, J., Kalin, R., \& Fleisher, C.J. 1994. Environmental controls on the petrology of a late Holocene speleothem from Botswana with annual layers of aragonite and calcite. Journal of Sedimentary Research, 64(1). 3

Railsback, L.B., Liang, F., Vidal Romaní, J.R., Grandal-d’Anglade, A., Vaqueiro Rodríguez, M., Santos Fidalgo, L., Fernández Mosquera, D., Cheng, H., \& Edwards, R.L. 2011. Petrographic and isotopic evidence for Holocene long-term climate change and shorter-term environmental shifts from a stalagmite from the Serra do Courel of northwestern Spain, and implications for climatic history across Europe and the Mediterranean. Palaeogeography, Palaeoclimatology, Palaeoecology, 305(1), 172-184. 3

Rasband, W.S. 1997-2012. ImageJ. Tech. rept. U.S. National Institutes of Health, U.S. National Institutes of Health, Bethesda, Maryland, USA. 7

Reynard, L.M., Day, C.C., \& Henderson, G.M. 2011. Large fractionation of calcium isotopes during caveanalogue calcium carbonate growth. Geochimica et Cosmochimica Acta, 75(13), 3726-3740. 10

Rickaby, R.E.M., \& Elderfield, H. 1999. Planktonic foraminiferal Cd/Ca: Paleonutrients or paleotemperature? Paleoceanography, 14(3), 293-303. 10

Rimstidt, J.D., Balog, A., \& Webb, J. 1998. Distribution of trace elements between carbonate minerals and aqueous solutions. Geochimica et Cosmochimica Acta, 62(11), 1851-1863. 10, 11, 12, 17, 30

Rosenthal, Y., Field, M.P., \& Sherrell, R.M. 1999. Precise determination of element/calcium ratios in calcareous samples using sector field inductively coupled plasma mass spectrometry. Analytical Chemistry, 71(15), 32483253. 6

Sherwin, C.M., \& Baldini, J.U.L. 2011. Cave air and hydrological controls on prior calcite precipitation and stalagmite growth rates: Implications for palaeoclimate reconstructions using speleothems. Geochimica Et Cosmochimica Acta, 75(14), 3915-3929. 12

Steefel, C.I., Van Cappellen P. 1990. A new kinetic approach to modeling water-rock interaction: The role of nucleation, precursors, and Ostwald ripening. Geochimica et Cosmochimica Acta, 54(10), 2657-2677. 5

Stumm, W., \& Morgan, J.J. 1996. Aquatic chemistry: chemical equilibria and rates in natural waters. 3rd ed edn. New York: Wiley. 5 
Tan, M., Baker, A., Genty, D., Smith, C., Esper, J., \& Cai, B. 2006. Applications of stalagmite laminae to paleoclimate reconstructions: comparison with dendrochronology/climatology. Quaternary Science Reviews, 25(17), 2103-2117. 3

Tang, J., Koehler, S.J., \& Dietzel, M. 2008. $\mathrm{Sr}^{2+} / \mathrm{Ca}^{2+}$ and ${ }^{44} \mathrm{Ca} /{ }^{40} \mathrm{Ca}$ fractionation during inorganic calcite formation: I. Sr incorporation. Geochimica et Cosmochimica Acta, 72(15), 3718-3732. 4

Tesoriero, A.J., \& Pankow, J.F. 1996. Solid solution partitioning of $\mathrm{Sr}^{2+}, \mathrm{Ba}^{2+}$, and $\mathrm{Cd}^{2+}$ to calcite. Geochimica et Cosmochimica Acta, 60(6), 1053-1063. 4, 16

Treble, P.C., Chappell, J., \& Shelley, J.M.G. 2005. Complex speleothem growth processes revealed by trace element mapping and scanning electron microscopy of annual layers. Geochimica et Cosmochimica Acta, 69(20), 4855-4863. 3

Turgeon, S., \& Lundberg, J. 2001. Chronology of discontinuities and petrology of speleothems as paleoclimatic indicators of the Klamath Mountains, Southwest Oregon, USA. Carbonates and Evaporites, 16(2), 153-167. 3

Vaks, A., Bar-Matthews, M., Matthews, A., Ayalon, A., \& Frumkin, A. 2010. Middle-Late Quaternary paleoclimate of northern margins of the Saharan-Arabian Desert: reconstruction from speleothems of Negev Desert, Israel. Quaternary Science Reviews, 29(19-20), 2647-2662. 3

Vaks, A, Gutareva, OS, Breitenbach, SFM, Avirmed, E, Mason, AJ, Thomas, AL, Osinzev, AV, Kononov, AM, \& Henderson, GM. 2013. Speleothems Reveal 500,000-Year History of Siberian Permafrost. Science. 3

Wang, X.F., Auler, A.S., Edwards, R.L., Cheng, H., Cristalli, P.S., Smart, P.L., Richards, D.A., \& Shen, C.C. 2004. Wet periods in northeastern Brazil over the past 210 kyr linked to distant climate anomalies. Nature, 432(7018), 740-743. 3

Zeebe, R.E., \& Wolf-Gladrow, D. 2005. $\mathrm{CO}_{2}$ in seawater: equilibrium, kinetics, isotopes. 65 . Elsevier oceanography series. 12 
A Plan View

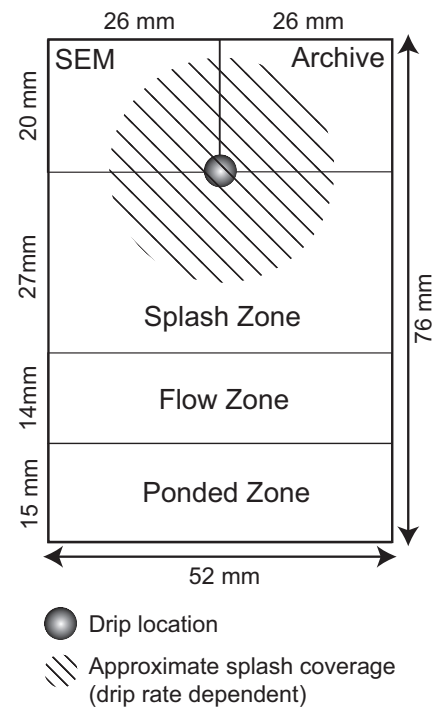

B Profile View

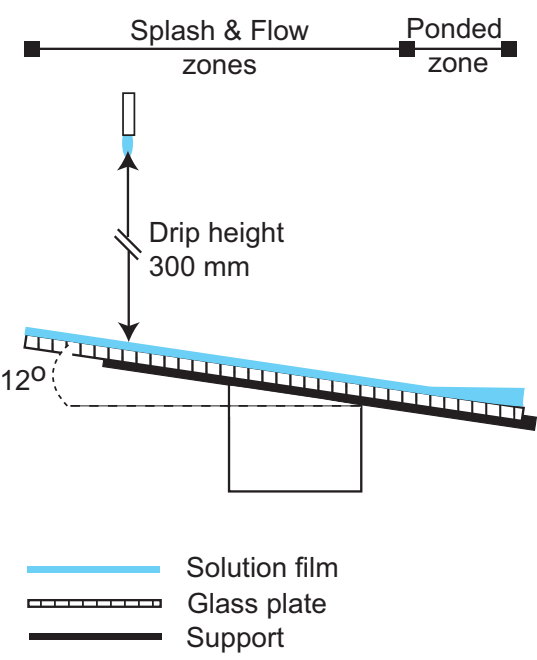

Figure 1: A: Plan view of the glass plate illustrating zones used for sample division. The filled circle is the point where the drip makes contact with the glass plate. The hashed circle is an approximate indication of the area covered by the splash generated by each drip, this varies with drip height and drip rate. 'SEM' is a portion of glass plate dedicated to in situ optical and scanning electron microscopy of the seed and sample crystals. 'Archive' contains in situ growth calcite for archive purposes. Down-flow of these, the plate is divided into three areas to allow the evolution of calcite chemistry to be assessed. The 'splash zone' contains a large percentage of the 'splashed' solution; the 'flow zone' receives a larger amount of solution flowing down from the 'upstream' areas; the 'ponded zone' has greater solution depth due to surface tension as the solution reaches the lower edge of the glass plates. B: Profile view of the glass plate as positioned within the precipitation box.

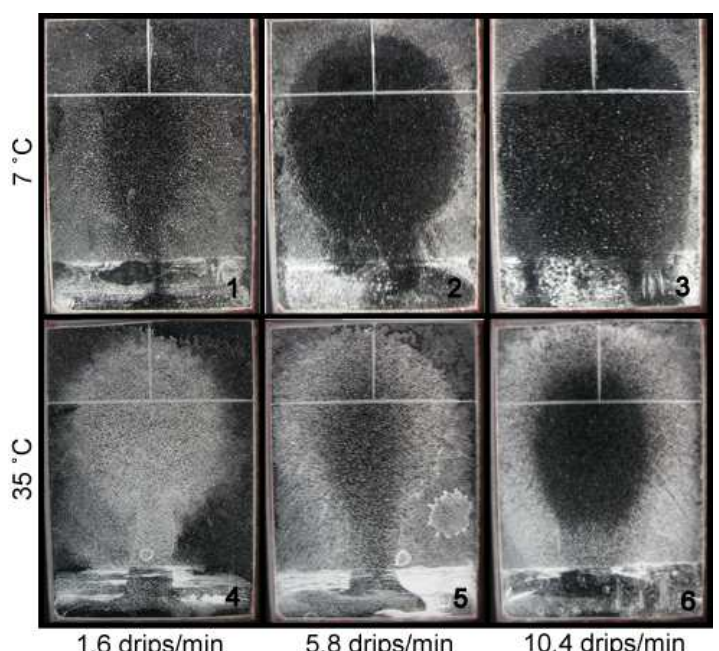

Figure 2: Post-experimental digital photographs of calcite sample growth for six out of the twelve experiments. The samples are back lit and the light is filtered through crossed polars to provide greater emphasis of the calcite growth areas. The calcite on the top row of plates was grown at $7^{\circ} \mathrm{C}$ with drip rate increasing from left to right, 1.6, 5.8 and 10.4 drips/min respectively. The same layout applies for the bottom row, for which the growth temperature was $35^{\circ} \mathrm{C}$. The 7 and $35^{\circ} \mathrm{C}$ experiments represent the smallest and largest growth masses achieved over the seven day period. 


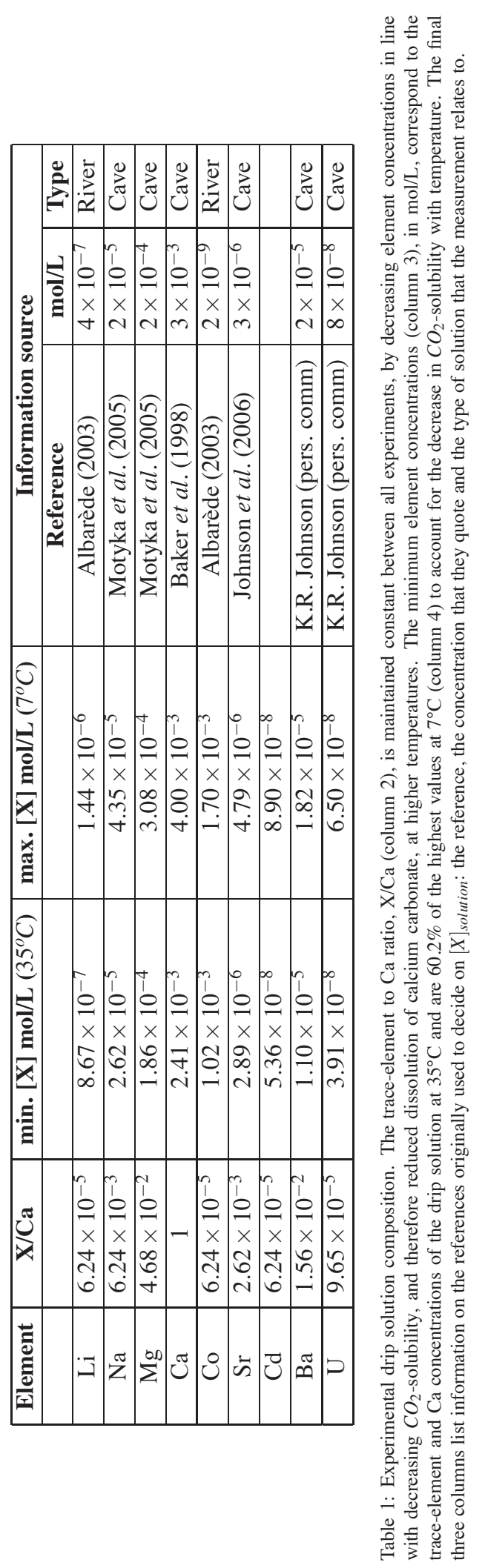




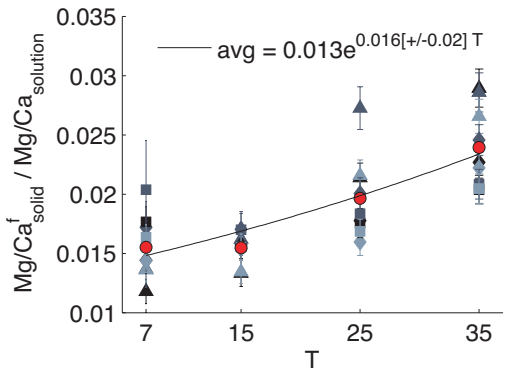

C

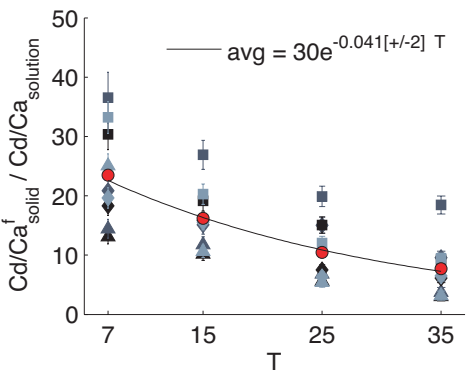

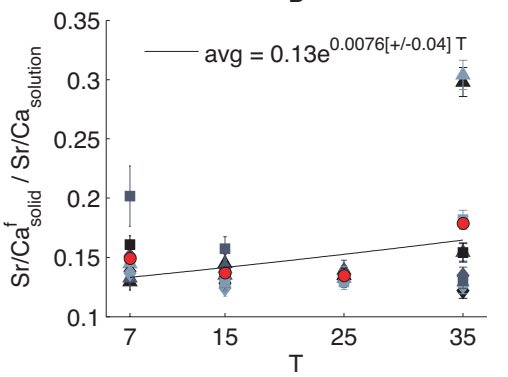

$\mathrm{D}$

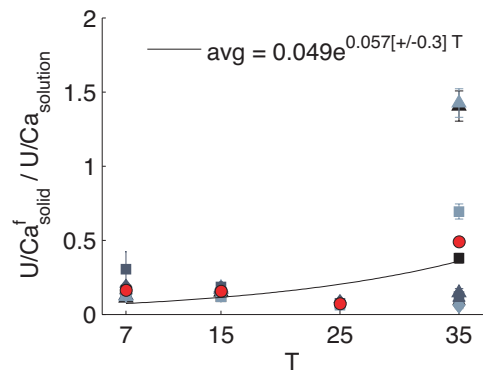

Shape:

$\triangle 1.6 \mathrm{drips} / \mathrm{min}$

$\checkmark 5.8 \mathrm{drips} / \mathrm{min}$

- $10.4 \mathrm{drips} / \mathrm{min}$

Colour:

- splash zone

- flow zone

- ponded zone

\section{- average}

for each

temperature

Figure 3: $\frac{X / C a_{\text {solid }}^{f}}{X / C a_{\text {slution }}^{f=1}}$ versus temperature for all drip rates and plate areas. Shapes denote drip rates with triangles, diamonds and squares denoting slow, medium and fast drip rates respectively. Greyscale colouring of these shapes denotes plate area, starting with black for the splash zone and shifting to lighter greys down-flow through the flow and ponded zones. Red circles represent the average value for each temperature and the black, continuous line is the exponential curve of best fit through these averages with the equation of best fit included in the key. 


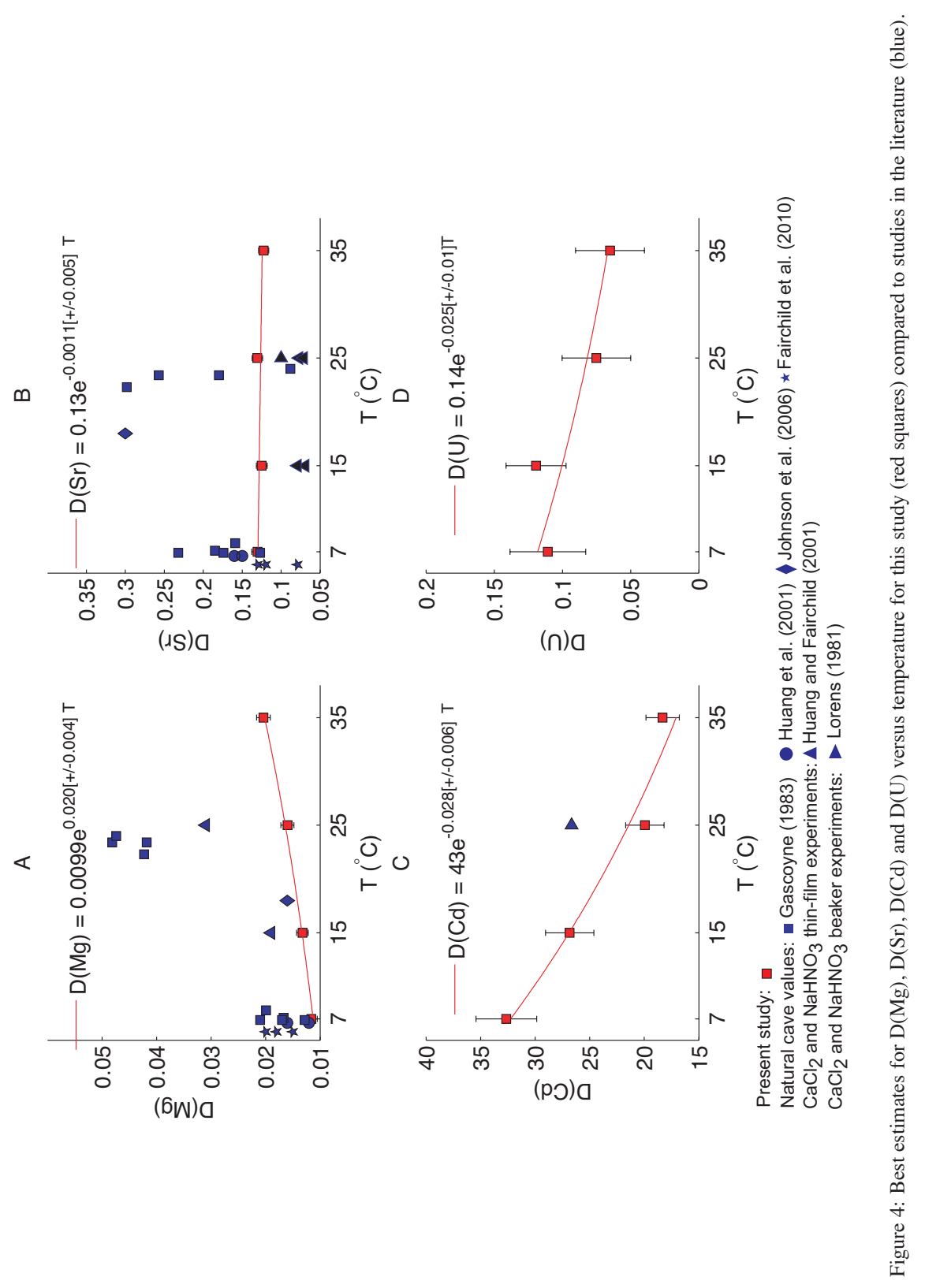



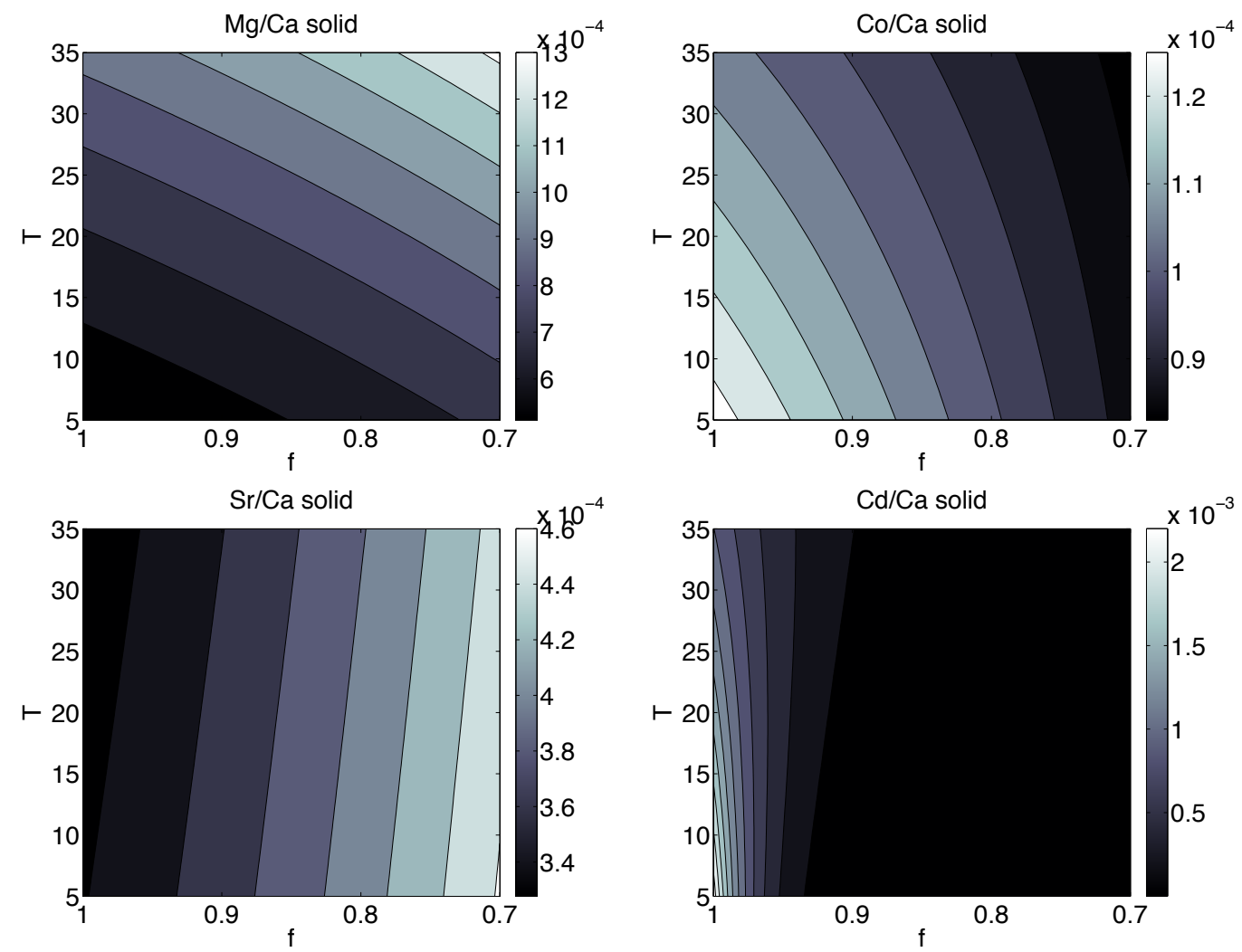

Figure 5: Calculated $X / \mathrm{Ca}_{\text {solid }}(f, T)$ plots for $\mathrm{Mg}, \mathrm{Co}, \mathrm{Sr}, \mathrm{Cd}$ with the response of $(X / \mathrm{Ca})_{\text {solid }}$ to $f$ modelled as a Rayleigh distillation process. Where contours are horizontal, $T$ is the dominant control on trace metal incorporation and where contours are vertical $f$ is the dominant control. Mg: $\mathrm{Mg}_{\mathrm{Ca}} \mathrm{Ca}_{\text {solid }}(f, T)=(\mathrm{Mg} / \mathrm{Ca})_{\text {solution }}^{0} \times\left(0.0099 \times e^{0.02 \times T}\right) \times f^{\left(0.0099 \times e^{0.02 \times T}\right)-1}$. Co: $\mathrm{Co} / \mathrm{Ca}_{\text {solid }}(f, T)=(\mathrm{Co} / \mathrm{Ca})_{\text {solution }}^{0} \times(2.1 \times$ $\left.e^{-0.0057 \times T}\right) \times f^{\left(2.1 \times e^{-0.0057 \times T}\right)-1}$. Sr: $S r / C a_{\text {solid }}(f, T)=(S r / C a)_{\text {solution }}^{0} \times\left(0.13 \times e^{-0.0011 \times T}\right) \times f^{\left(0.13 \times e^{-0.0011 \times T}\right)-1}$. Cd: $C d / C a_{\text {solid }}(f, T)=$ $(\mathrm{Cd} / \mathrm{Ca})_{\text {solution }}^{0} \times\left(43 \times e^{-0.028 \times T}\right) \times f^{\left(43 \times e^{-0.028 \times T}\right)-1}$. 


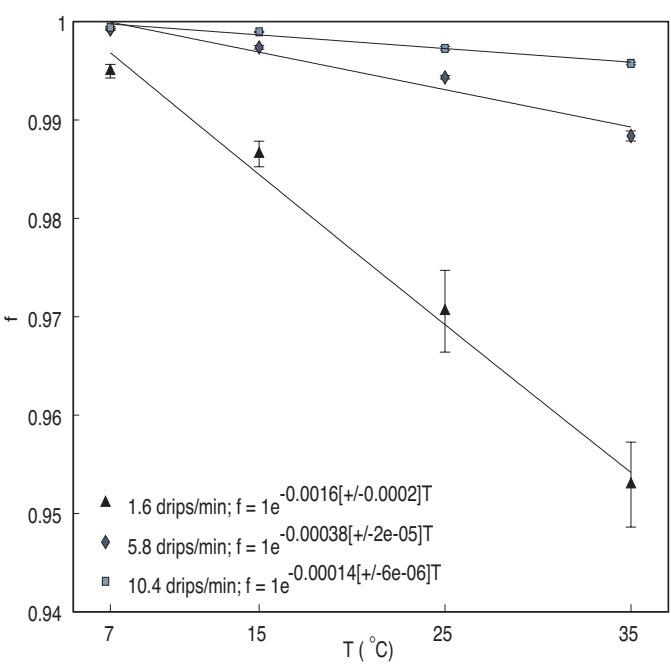

B

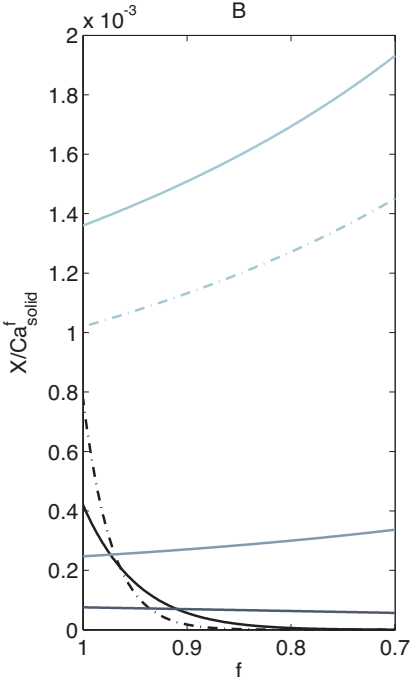

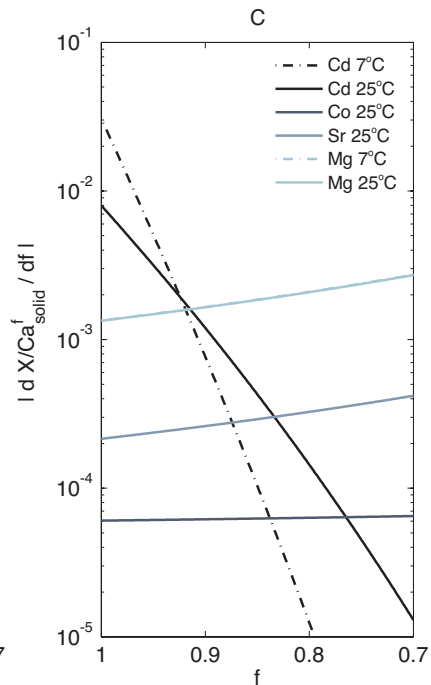

Figure 6: $\mathbf{A}: f$ plotted against temperature for splash zone calcite precipitation at slow, medium and fast drip rates. B: $X / C a^{f} l_{i d}$ plotted against $f$ for trace-elements $\mathrm{Mg}, \mathrm{Co}, \mathrm{Sr}$ and $\mathrm{Cd}$ at $25^{\circ} \mathrm{C}$ (equation 4). Additional curves for $\mathrm{Mg}$ and $\mathrm{Cd}$ at $7{ }^{\circ} \mathrm{C}$ are plotted as dashed lines. The values for $X / C a_{\text {solution }}^{f=1}$ and $D(X)$ are taken from the present study. C: Absolute value of the slopes of curves in subplot B plotted against $f$, i.e. $\left|\frac{d X / C a_{\text {solid }}^{f}}{d f}\right|$ plotted against $f$. Plotting the absolute value of the derivative facilitates comparison of the magnitude of the slopes for different elements. The higher the curve in this subplot, the more sensitive the trace-element is to $f$ for these experimental conditions.

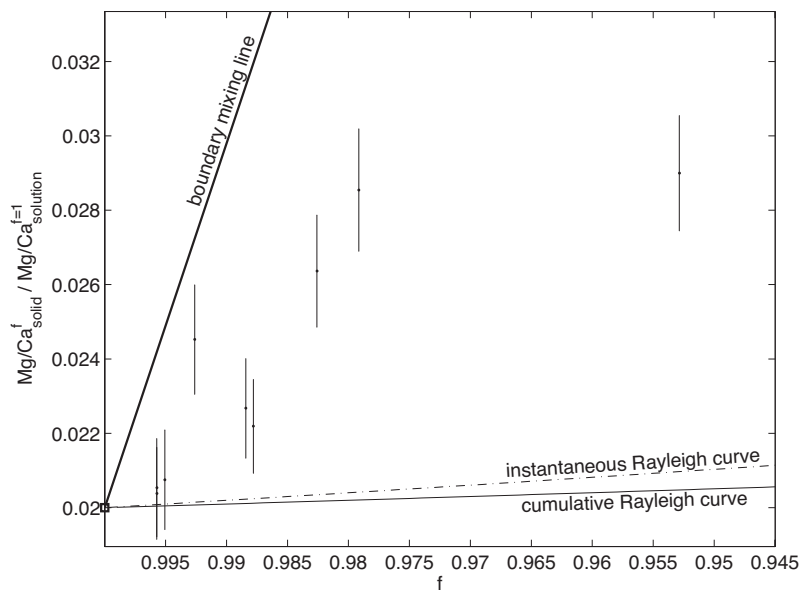

Figure 7: $\mathrm{Mg} / \mathrm{Ca}_{\text {solid }}^{f} / \mathrm{Mg} / \mathrm{Ca}_{\text {solution }}^{f=1}$ plotted against $f$ (estimated as $1-\frac{\text { mass precipitated Ca }}{\text { massdissolvedCaflowingover plate }}$ ) for the 9 measurements at $35^{\circ} \mathrm{C}$. The dashed (continuous) line is the instantaneous (cumulative) Rayleigh curve assuming the measured D(Mg) (table 3$) . M g / C a_{\text {solid }}^{f} / M g / C a_{\text {solution }}^{f=1}$ measurements are not all within error of these Rayleigh curves. The thick continuous line is the mixing line between solids precipitated from solution with $f \backsim 1$ and solids precipitated from solution with $f \backsim 0$. All measurements lie between this mixing line and the Rayleigh curves. 


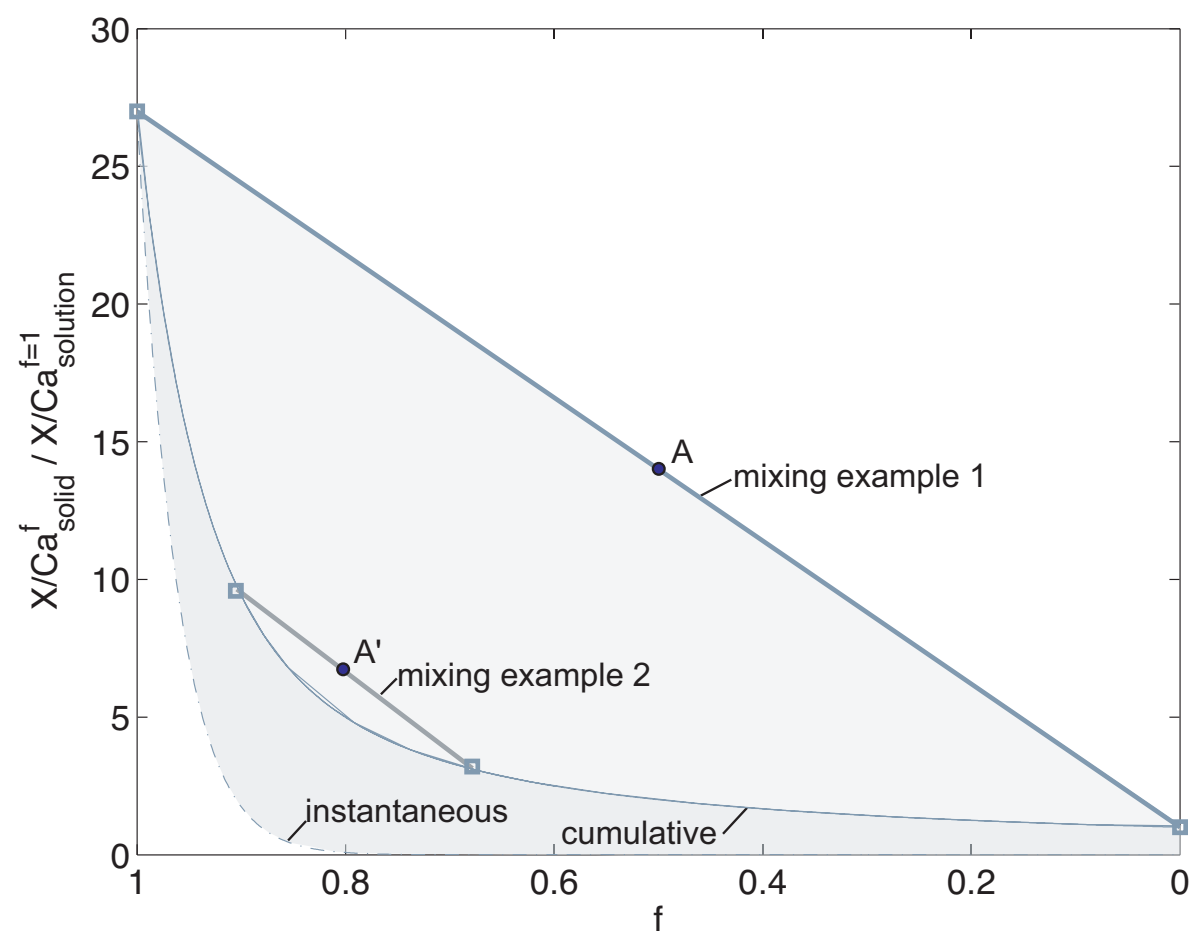

Figure 8: Cartoon representation of the effect of mixing calcite precipitation from solutions with different fractions of calcite growth $(f)$. The curves illustrated here are for $D(X)=27$, as applies to $\mathrm{Cd}$ at $15^{\circ} \mathrm{C}$. For no mixing, we expect $\frac{(\mathrm{X} / \mathrm{Ca})_{\text {solid }}^{f}}{(\mathrm{X} / \mathrm{Ca})_{\text {solution }}^{f}}$ to lie between the instantaneous and the cumulative Rayleigh curves. Mixing of carbonate formed at more than one value of $f$ moves the values towards the top right of the figure. For instance, a simple and extreme mixing scenario is 1:1 mixing of solids formed from solutions with $f \sim 1$ and $f \sim 0$ (point A of mixing example 1). An infinite number of other mixing lines exist (e.g. mixing line example 2). Mixing can cause significant deviation from simple Rayleigh fractionation during stalagmite growth.

\begin{tabular}{|c|c|c|c|}
\hline Element & This study & Rimstidt et al. (1998) & Temp. range \\
\hline $\mathrm{Mg}$ & $D(\mathrm{Mg})=0.0099 e^{0.02[ \pm 0.003] T}$ & $D(\mathrm{Mg})=0.012 e^{0.023 T}$ & 7 to $35^{\circ} \mathrm{C}$ \\
\hline $\mathrm{Co}$ & $D(\mathrm{Co})=2.1 e^{-0.0057[0.01] T}$ & $D(\mathrm{Co})=9.1 e^{0.005 T}$ & 25 and $35^{\circ} \mathrm{C}$ \\
\hline $\mathrm{Sr}$ & $D(\mathrm{Sr})=0.13 e^{-0.0011[ \pm 0.005] T}$ & $D(\mathrm{Sr})=0.09 e^{-0.003 T}$ & 7 to $35^{\circ} \mathrm{C}$ \\
\hline $\mathrm{Cd}$ & $D(\mathrm{Cd})=43 e^{-0.028[ \pm 0.006] T}$ & $D(\mathrm{Cd})=235 e^{-0.012 T}$ & 7 to $35^{\circ} \mathrm{C}$ \\
\hline $\mathrm{Ba}$ & $D(\mathrm{Ba})=0.11 e^{0.0011[ \pm 0.01] T}$ & $D(\mathrm{Ba})=0.02 e^{0.0004 T}$ & 25 and $35^{\circ} \mathrm{C}$ \\
\hline $\mathrm{U}$ & $D(\mathrm{U})=0.14 e^{-0.025[ \pm 0.01] T}$ & & 7 to $35^{\circ} \mathrm{C}$ \\
\hline
\end{tabular}

Table 2: Comparison between this study and Rimstidt et al. (1998) of $D(X)$ and the relationships between $D(X)$ and temperature. An exponential best-fit curve was fitted to the Rimstidt et al. (1998) predictions to facilitate comparison. 'Temp. range' indicates the temperatures at which measurements were made for our experiments, i.e. $7,15,25$ and $35^{\circ} \mathrm{C}$ for all elements except $\mathrm{Ba}$ and $\mathrm{Co}$, which were measured at 25 and $35^{\circ} \mathrm{C}$ only. 


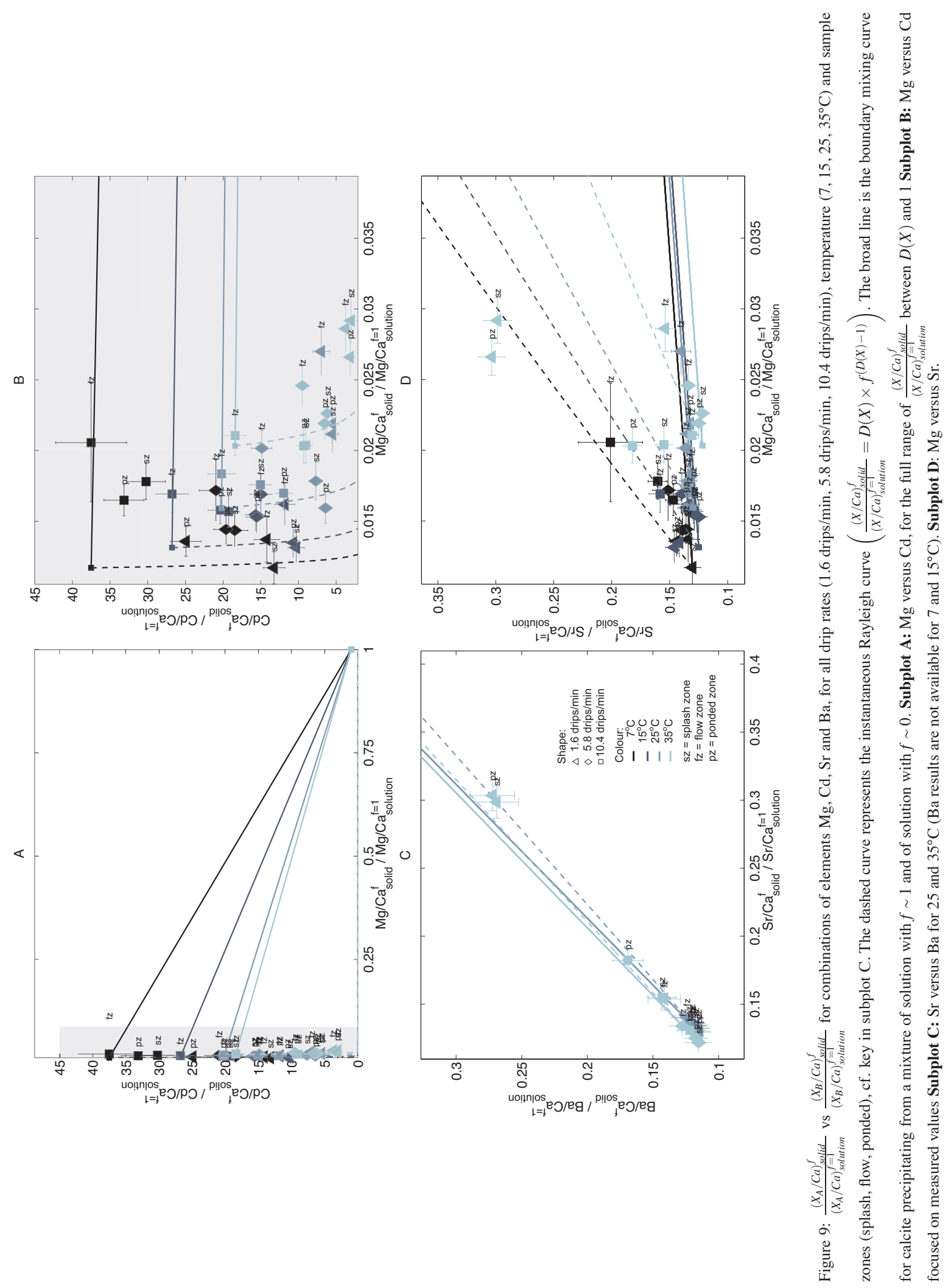




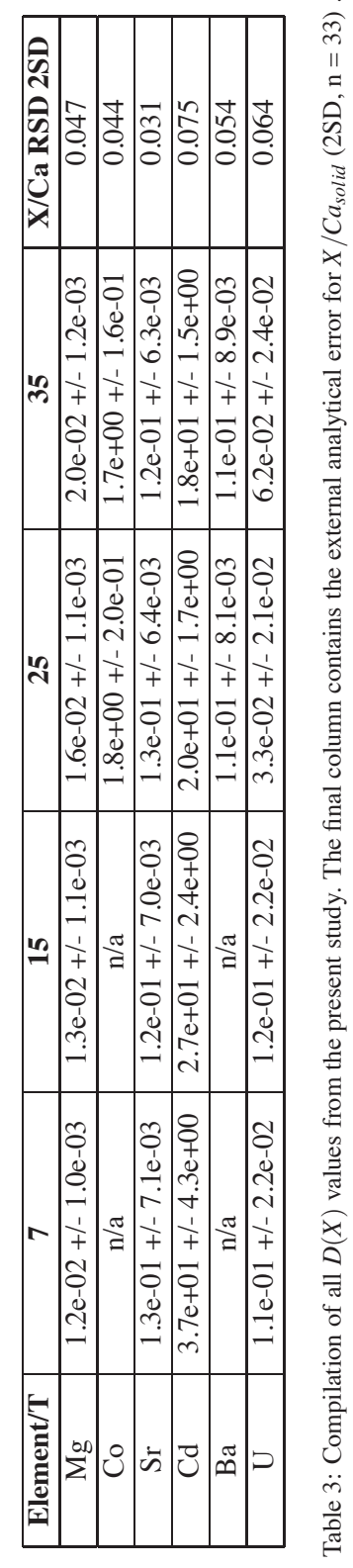


Click here to download Electronic Annex: Supplementary_Material.pdf 